US Army Corps

of Engineers

Waterways Experiment

Station

Installation Restoration Research Program

\title{
Fate of 2,4,6-Trinitrotoluene in a Simulated Compost System
}

\author{
by Judith C. Pennington, Karen F. Myers, \\ Douglas Gunnison, Erika F. McCormick, WES
}

Charolett A. Hayes, Michael Ochman, Deborah R. Felt, AScl Corporation

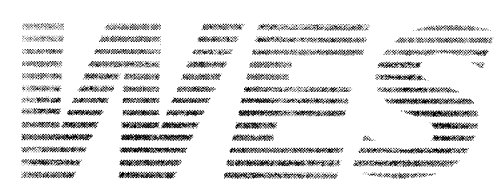

Approved For Public Release; Distribution Is Unlimited

Prepared for Headquarters, U.S. Army Corps of Engineers 
The contents of this report are not to be used for advertising, publication, or promotional purposes. Citation of trade names does not constitute an official endorsement or approval of the use of such commercial products. 


\section{Fate of 2,4,6-Trinitrotoluene in a Simulated Compost System}

by Judith C. Pennington, Karen F. Myers, Douglas Gunnison, Erika F. McCormick

U.S. Army Corps of Engineers

Waterways Experiment Station 3909 Halls Ferry Road

Vicksburg, MS 39180-6199

Charolett A. Hayes, Michael Ochman, Deborah R. Felt

AScl Corporation 1365 Beverly Road

McLean, VA 22101

Final report

Approved for public release; distribution is unlimited 


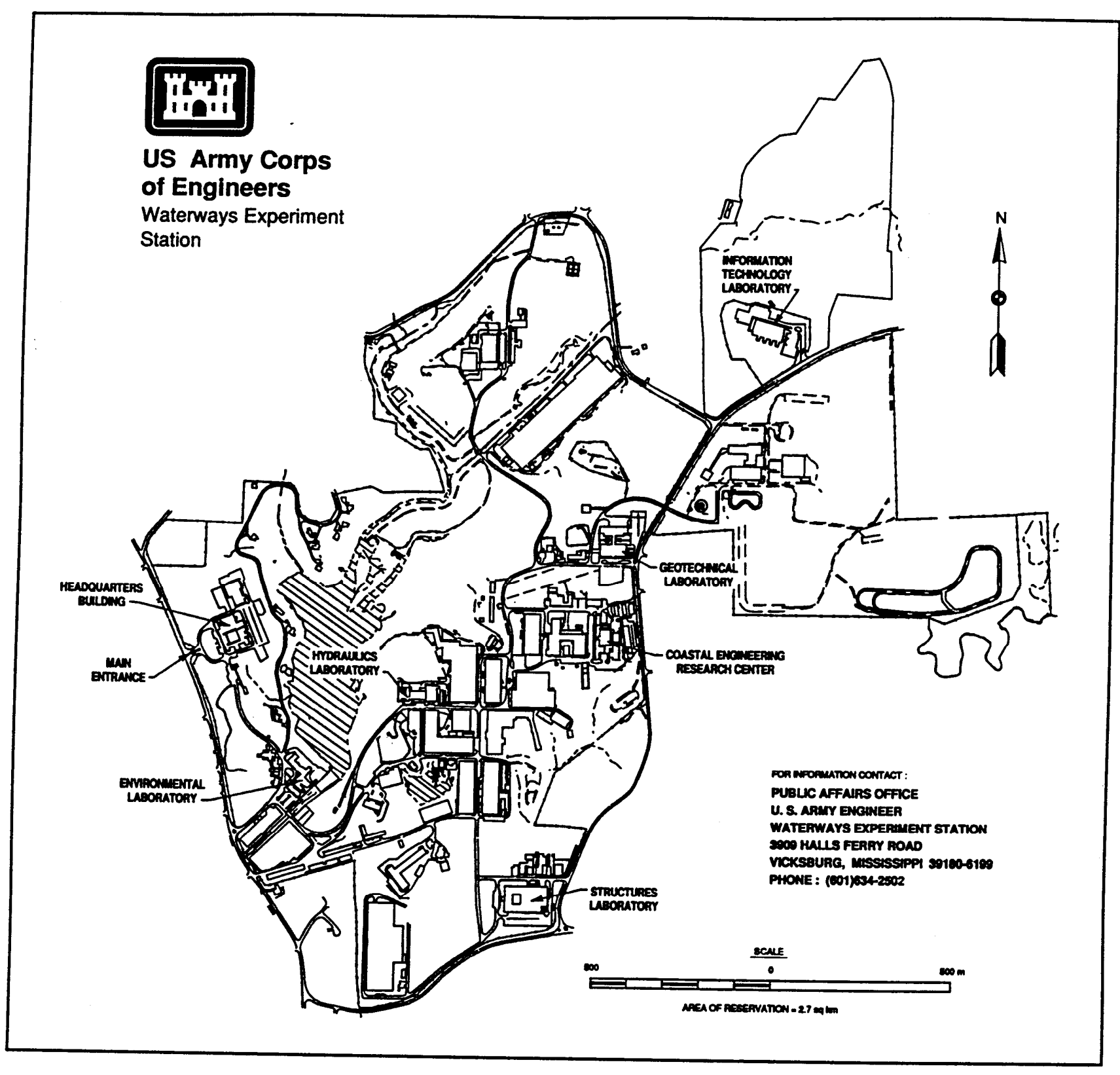

\section{Waterways Experiment Station Cataloging-In-Publication Data}

Fate of 2,4,6-Trinitrotoluene in a simulated compost system / by Judith C. Pennington ... [et al.] ; prepared for U.S. Army Corps of Engineers. 60 p. : ill. ; $28 \mathrm{~cm}$. - (Technical report ; IRRP-94-2)

Includes bibliographic references.

1. Compost. 2. Explosives. 3. Humification. 4. Nitrotoluene. I. Pennington, Judith C. II. United States. Army. Corps of Engineers. III. U.S. Army Engineer Waterways Experiment Station. IV. Installation Restoration Research Program. V. Series: Technical report (U.S. Army Engineer Waterways Experiment Station) ; IRRP-94-2.

TA7 W34 no.IRRP-94-2 


\section{Contents}

Preface $\ldots \ldots \ldots \ldots \ldots \ldots \ldots \ldots \ldots \ldots \ldots \ldots \ldots$ vi

1 -Introduction $\ldots \ldots \ldots \ldots \ldots \ldots \ldots \ldots \ldots \ldots \ldots \ldots$

Background and Rationale $\ldots \ldots \ldots \ldots \ldots \ldots \ldots$

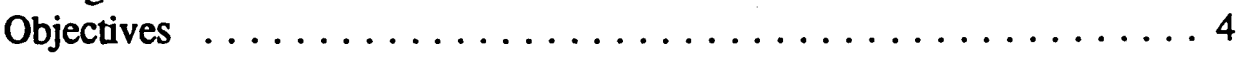

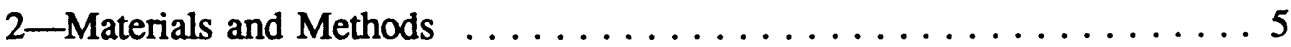

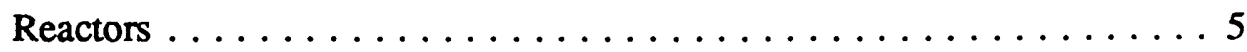

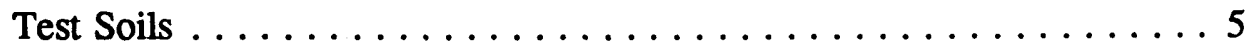

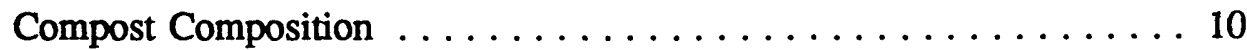

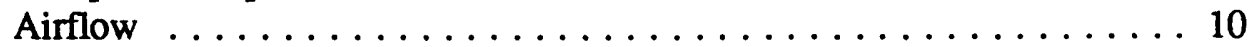

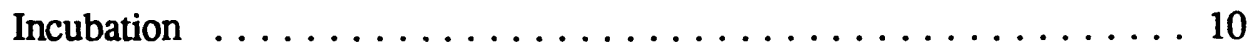

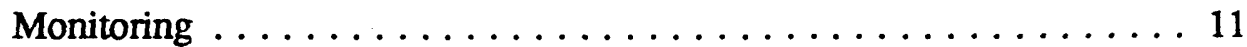

Analysis of Compost $\ldots \ldots \ldots \ldots \ldots \ldots \ldots \ldots \ldots \ldots \ldots$

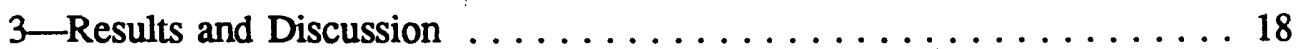

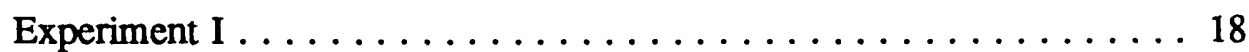

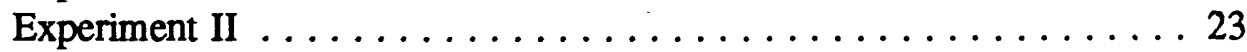

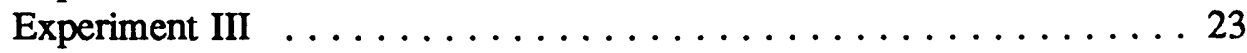

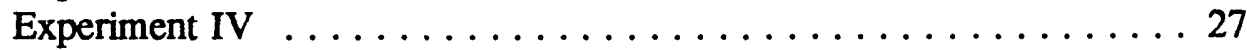

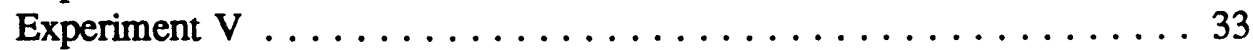

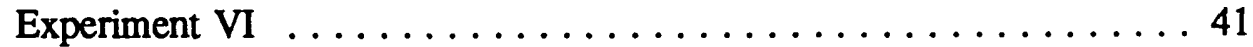

4 -Conclusions ........................ 48

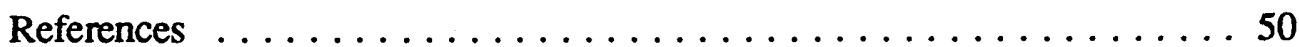

SF 298

\section{List of Figures}

Figure 1. Model of mass balance showing various compartments potentially occupied by TNT and/or its degradation or transformation products after composting 
Figure 2. Small-scale composting system including precompost and post-compost air-scrubbing traps, and temperature-monitoring system $\ldots \ldots \ldots \ldots \ldots \ldots \ldots \ldots \ldots \ldots \ldots \ldots \ldots \ldots \ldots \ldots$

Figure 3. Extraction and fractionation scheme for composted material

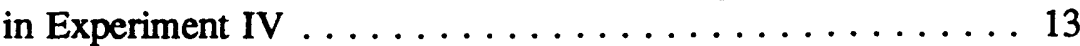

Figure 4. Extraction and fractionation scheme for composted material in Experiment $\mathrm{V} \ldots \ldots \ldots \ldots \ldots \ldots \ldots \ldots$

Figure 5. Extraction and fractionation scheme for composted material in Experiment VI . . . . . . . . . . . . . . 15

Figure 6. Mean daily maximum, average, and minimum temperature in composted clay and silt reactors from Experiment I . . . . . 19

Figure 7. Daily total carbon dioxide evolved from each reactor from

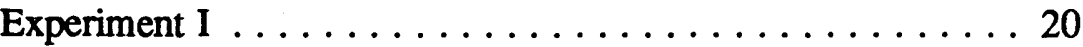

Figure 8. Microbial populations as determined by direct plate counts of composted clay and silt from Experiments I and II . . . . 21

Figure 9. Daily total carbon dioxide evolved from each reactor from Experiment II ................... 24

Figure 10. Mean daily maximum, average, and minimum temperatures in composted clay and silt reactors from Experiment II . . . 25

Figure 11. Daily total carbon dioxide evolved from each reactor from Experiment III . . . . . . . . . . . . . . . . 27

Figure 12. Mean daily maximum, average, and minimum temperatures in composted clay and silt reactors from Experiment III . . . . 28

Figure 13. Mean daily maximum, average, and minimum temperatures in composted clay and silt reactors from Experiment IV . . . . 30

Figure 14. Daily total carbon dioxide evolved from each reactor from Experiment IV . . . . . . . . . . . . . . . . 31

Figure 15. Microbial populations as determined by direct plate counts of composted clay and silt from Experiment IV . . . . . . 32

Figure 16. Mean daily maximum, average, and minimum temperatures in composted Umatilla soil from Experiment $\mathrm{V} \ldots \ldots \ldots . .35$

Figure 17. Daily total carbon dioxide evolved from each reactor from

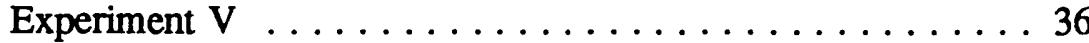

Figure 18. Microbial populations as determined by direct plate counts of composted Umatilla soil from Experiment V . . . . . . 37

Figure 19. Percent recovery of added radioactivity in each fraction of composted Umatilla soil in Experiment V . . . . . . . . . . . 39

Figure 20. Results of HPLC/UV analysis of composted Umatilla soil from Experiment $\mathrm{V}$ at $\mathrm{T}_{0}$ and $\mathrm{T}_{20} \ldots \ldots \ldots \ldots \ldots$ 
Figure 21. Mean daily maximum, average, and minimum temperatures in composted Umatilla reactors from Experiment VI . . . . 42

Figure 22. Daily total carbon dioxide evolved from each reactor from Experiment VI . . . . . . . . . . . . . . 43

Figure 23. Microbial populations as determined by direct plate counts of composted Umatilla soil from Experiment VI . . . . . . . 44

Figure 24. Percent recovery of added radioactivity in each fraction of composted Umatilla soil in Experiment VI . . . . . . . 46

Figure 25. Results of HPLC/UV analysis of composted Umatilla soil at $\mathrm{T}_{0}$ and $\mathrm{T}_{20}$ in Experiment $\mathrm{VI} \ldots \ldots \ldots \ldots \ldots \ldots$

\section{List of Tables}

Table 1. Characteristics of Test Soils $\ldots \ldots \ldots \ldots \ldots \ldots$

Table 2. Explosives Analysis of Umatilla Soil $\ldots \ldots \ldots \ldots \ldots \ldots$

Table 3. Composition of Peptone, Tryptone, Yeast Extract, Glucose Medium .................... 12

Table 4. Percent Recoveries of Radiolabel from All Compartments in

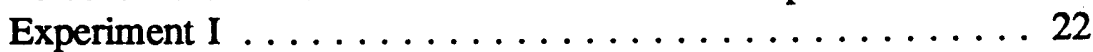

Table 5. Percent Recoveries of Radiolabel from All Compartments in Experiment II .................. 26

Table 6. Mean Operational Parameters for Experiment III . . . . . 26

Table 7. Percent Recoveries of Radiolabel from All Compartments in Experiment III . . . . . . . . . . . . . . . 29

Table 8. Bulk Densities Before and After Composting . . . . . . 33

Table 9. Percent Recoveries of Radioactivity from Unfractionated Compartments in Experiment IV . . . . . . . . 33

Table 10. Percent Recoveries of Radioactivity from Compost Fractions

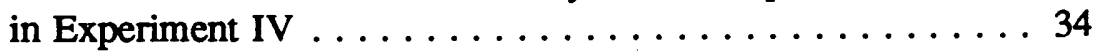

Table 11. Percent Recoveries of Radioactivity from Unfractionated Compartments in Experiment V . . . . . . . . . . 37

Table 12. Percent Recoveries of Radioactivity from Unfractionated Compartments in Experiment VI . . . . . . . . 45 


\section{Preface}

The work reported herein was conducted by the Environmental Laboratory (EL) of the U.S. Army Engineer Waterways Experiment Station (WES), Vicksburg, MS, as part of the Installation Restoration Research Program (IRRP) and the U.S. Army Environmental Quality Technology Research Program, Work Unit AF25-ET-001.

Dr. Clem Meyer was the IRRP Coordinator at the Directorate of Research and Development, Headquarters, U.S. Army Corps of Engineers. Captain Kevin Keehan was the Technical Monitor for the U.S. Army Environmental Center, and Mr. Richard Waples was the Technical Monitor for the U.S. Army Corps of Engineers Military Programs. Dr. John Cullinane, WES, was the IRRP Program Manager.

Personnel who cooperated in the execution of the study and the preparation of this report include Dr. Judith C. Pennington, Principal Investigator, and Dr. Douglas Gunnison, Ecosystem Processes and Effects Branch (EPEB), Environmental Processes and Effects Division (EPED), EL; Ms. Charolett A. Hayes, Mr. Michael Ochman, and Ms. Deborah R. Felt, AScI Corporation, McLean, VA; and Mses. Karen F. Myers and Erika F. McCormick, Environmental Chemistry Branch (ECB), Environmental Engineering Division (EED), EL. The report was reviewed by Drs. James M. Brannon and William M. Davis, EPEB, and Dr. Victor A. McFarland, Fate and Effects Branch, EPED.

The report was prepared under the general supervision of Dr. Richard E. Price, Acting Chief, EPEB; Mr. Donald L. Robey, Chief, EPED; Ms. Ann B. Strong, Chief, ECB; Dr. Raymond L. Montgomery, Chief, EED; and Dr. John W. Keeley, Director, EL.

At the time of publication of this report, Director of WES was Dr. Robert W. Whalin. Commander was COL Bruce K. Howard, EN. 
This report should be cited as follows:

Pennington, J. C., Hayes, C. A., Myers, K. F., Ochman, M., Gunnison, D., Felt, D. R., and McCormick, E. F. (1994). "Fate of 2,4,6-trinitrotoluene in a simulated compost system,"

Technical Report IRRP-94-2, U.S. Army Engineer Waterways Experiment Station, Vicksburg, MS. 


\section{Introduction}

\section{Background and Rationale}

Composting is generally defined as a microbial process for conversion of organic wastes into humus under aerobic, thermophilic conditions (Woodward 1990). At least three components are required: organic material to reduce bulk weight and provide substrate for microbial metabolism; bulking agents to provide structure and aeration; and a source of active microorganisms (Haug 1980).

Factors that affect composting efficiency include moisture, temperature, aeration, and carbon-to-nitrogen ratio of the organic material. Moisture optima vary with the type of bulking materials used, but are typically between 40 and 60 percent by weight (Wilson 1989). In typical compost piles, temperatures rise from ambient through mesophilic $\left(25\right.$ to $35^{\circ} \mathrm{C}$ ) and thermophilic (45 to $65^{\circ} \mathrm{C}$ ) to $70^{\circ} \mathrm{C}$ or more, at which even the thermophilic microorganisms are inactivated, and the temperature declines as the microbes die. Aerobic microbial activity for decomposition of organic matter is typically much faster and more efficient than anaerobic activity (Alexander 1977). However, decomposition of some organic contaminants may be favored by anaerobic activity (McCormick, Cornell, and Kaplan 1984). Nonetheless, composting is ordinarily considered an aerobic process (Woodward 1990). Therefore, aeration to oxygen levels of 5 to 15 percent are suggested (Stentiford, Mara, and Taylor 1985). The ratio of available carbon to nitrogen ( $C / N$ ratio) is an important factor controlling metabolism by microorganisms. In compost, the ideal $\mathrm{C} / \mathrm{N}$ ratio is generally considered to be 20 to 30 parts carbon to each part nitrogen (Haug 1980).

Results of pilot and field studies at the Umatilla Munitions Depot Activity (UMDA) indicated that composting of explosives-contaminated soils is an attractive and economical altemative to incineration (Williams and Marks 1991). Results of compost analysis after 90 days when 10 percent of the compost was explosives-contaminated soil indicated a 98-percent reduction in TNT (Griest et al. 1991). Analysis for several well-known transformation products of 2,4,6-trinitrotoluene (TNT); 4-amino-2,6-dinitrotoluene (4ADNT); 2-amino4,6-dinitrotoluene (2ADNT); 2,4-diamino-6-nitrotoluene (24DANT); and 2,6diamino-4-nitrotoluene (26DANT) indicated a general increase in 4ADNT until 
90 days (sampled at $0,10,20,44$, and 90 days) when a decrease was observed. Small amounts of 24DANT and 26DANT appeared at 44 and 90 days. Production of these transformation products was insufficient to account for all of the loss of TNT observed. These results suggest that TNT was either mineralized or became integrated into the compost matrix in a form that was unextractable by methods recommended for analysis of TNT in soils.

Mass balance studies to resolve these two potential mechanisms of TNT disappearance required use of a small-scale system that adequately simulated the composting process. Mass balance of an experimental system is achieved when all of the material of interest that was introduced into the test system, e.g., TNT, can be accounted for at the end of the experiment. The goal of the mass balance determination is to account for 100 percent of the added material. However, experimental error often reduces total recovery.

The end products of composting of TNT-contaminated soils may be simple inorganic constituents such as carbon dioxide, slightly more complex volatile compounds, extractable or unextractable transformation or degradation products, and/or the unchanged parent compound. "Compartments" into which the final products may move include the following: carbon dioxide, volatile organic compounds (VOCs), extractable compounds, and unextractable compounds (Figure 1). Since the transformation/degradation pathway for TNT in compost is undefined, only a few of the potential products of TNT are known. Furthermore, methods for analysis of unextractable compounds are undeveloped. The best method for tracing TNT and any products into each compartment is to use radiolabeled $\left[{ }^{14} \mathrm{C}\right] \mathrm{TNT}$. Therefore, uniformly ring-labeled TNT was added to the tests.

Mass balance was determined by assaying each compartment for radioactivity. The model for mass balance (Figure 1) includes a summation of the percent of added radioactivity found in each compartment and an error term representing any unaccounted for remainder; the smaller the error term, the better the mass balance. Procedures for analyzing each compartment for the radioisotope were developed. Concurrently assaying each compartment for TNT and its transformation or degradation products by an analytical method capable of identifying products is desirable since measuring radioactivity only indicates the compartment in which ${ }^{14} \mathrm{C}$ resides. Therefore, all extractable compartments were analyzed by high performance liquid chromatography (HPLC) for TNT and known transformation products of TNT. The available HPLC methods require removal of the compounds from the solid phase by extraction with organic solvents. However, not all of the compounds potentially formed are extractable (Pennington 1988). In fact, if humification of the TNT has occurred, detection of the humification products by any method except radioactivity of the added radiolabeled TNT will not be possible. Nevertheless, analysis of the extractable material contributes to an understanding of the ultimate fate of TNT in the composting process. 


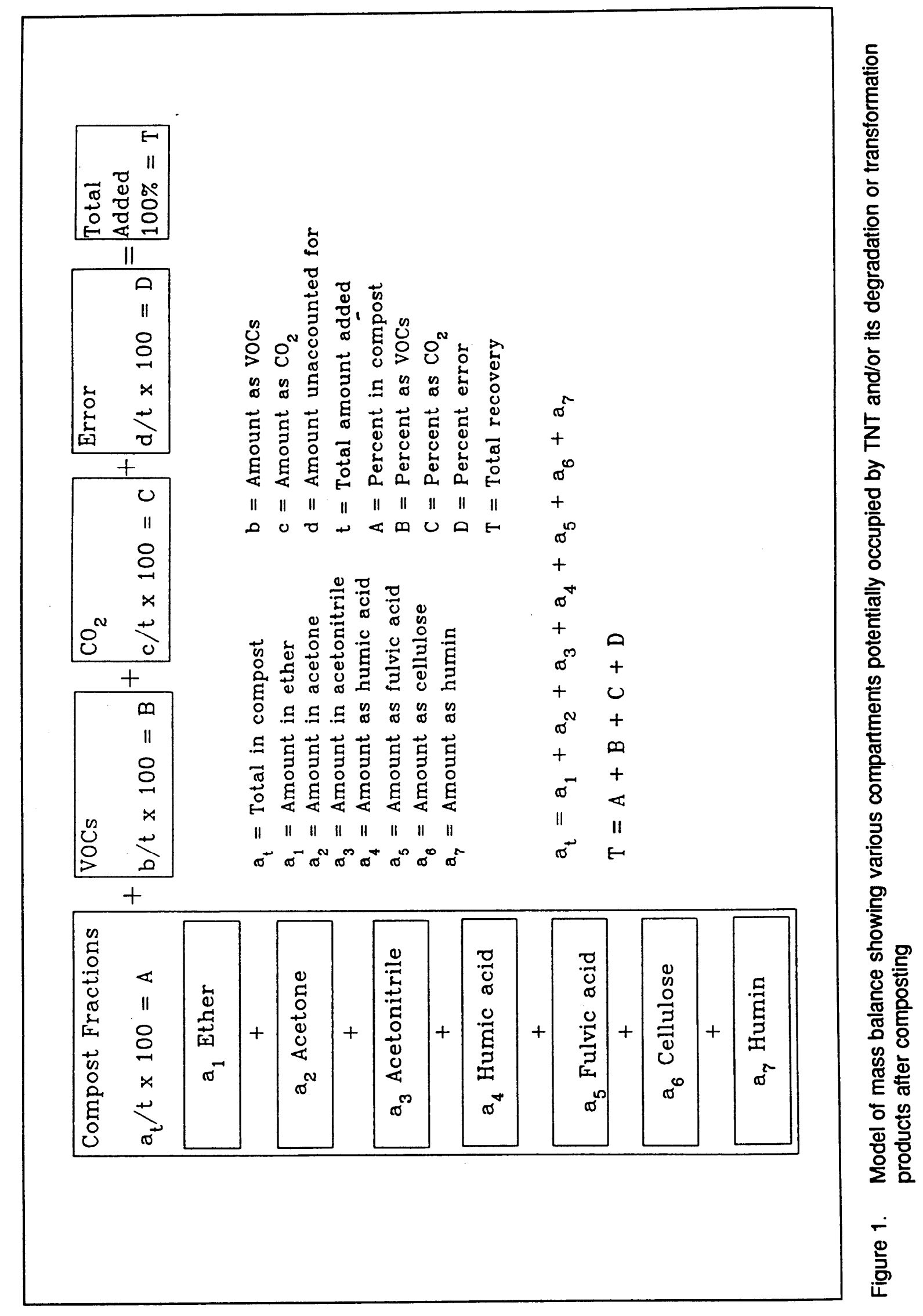




\section{Objectives}

The overall objective of the study was to develop a mass balance of TNT in a small-scale compost system. Objectives of each of the six small-scale experiments were as follows:

Experiment I: $\quad$ Verify that composting of TNT occurs in the smallscale test system and refine analytical techniques.

Experiment II: Monitor the microbial behavior of the small-scale test system and refine procedures for microbial analysis of composting.

Experiment III: Determine mass balance in the small-scale test system under mesophilic conditions.

Experiment IV: Determine the fate of TNT in simulated thermophilic conditions using a TNT-amended soil.

Experiment V: Determine the effects of abiotic processes on the fate of TNT in the compost matrix.

Experiment VI: Determine the fate of TNT in simulated thermophilic conditions at a small scale using a field-contaminated soil. 


\section{Materials and Methods}

\section{Reactors}

A modification of a test chamber described by Magalhaes et al. (1991) was adopted for this study. The test chamber consisted of wide-mouthed glass canning jars $\left(473 \mathrm{~cm}^{3}\right)$ with modified lids (Figure 2). Lids were equipped with an air inlet and an air outlet port as well as thermocouple and sampling ports. A false bottom was made of $0.3-\mathrm{cm}$ plexiglass with a $5.1-\mathrm{cm}$ opening. The false bottom held the compost $1.5 \mathrm{~cm}$ off the bottom of the reactor. The opening was covered with air-permeable polyester fabric to prevent compost from falling to the bottom of the jar and to allow airflow throughout the compost. The plexiglass also served as a baffle to prevent air from passing along the walls of the jar rather than through the compost.

\section{Test Soils}

Sharkey clay and Tunica silt (Table 1) were amended with radiolabeled TNT for Experiments I-IV, and UMDA soil (Tables 1 and 2) was amended with radiolabeled TNT for Experiments V and VI. Soils were characterized after air drying and sieving to 2-mm maximum particle size. Oven dry weight (ODW) was determined by drying $1 \mathrm{~g}$ of wet soil at $105^{\circ} \mathrm{C}$ to constant weight. Particle-size distribution for all test soils was determined by the method of Day (1956) as modified by Patrick (1958). Total organic carbon was determined by American Public Health Association (1989) Method 5310 D. Cation-exchange capacity was determined by the ammonium saturation method (Plumb 1981). Extracts were analyzed according to U.S. Environmental Protection Agency (EPA) Standard Method 350.1 (EPA 1982). Soil $\mathrm{pH}$ was determined on magnetically stirred soil slurries (1:2, soil:water) using a Beckman Model SS-3 pH meter (Beckman Instruments Inc., Fullerton, CA). Oxalate extractable $\mathrm{Fe}, \mathrm{Al}, \mathrm{Mn}$, and $\mathrm{Ca}$ were determined according to the method of Brannon and Patrick (1985). Metals were assayed on a Beckman Spectra Span IIIB Argon Plasma Emission Spectrophotometer (Applied Research Laboratories, Dearborn, MI). The UMDA soil was analyzed for explosives by EPA SW-846 Method 8330 (EPA 1990). Analytes included TNT, 1,3,5-trinitro-1,3,5-hexahydrotriazine (RDX), 1,3,5,7-tetranitrooctahydro1,3,5,7-tetrazocine (HMX), tetryl, 1,3-dinitrobenzene (DNB), 


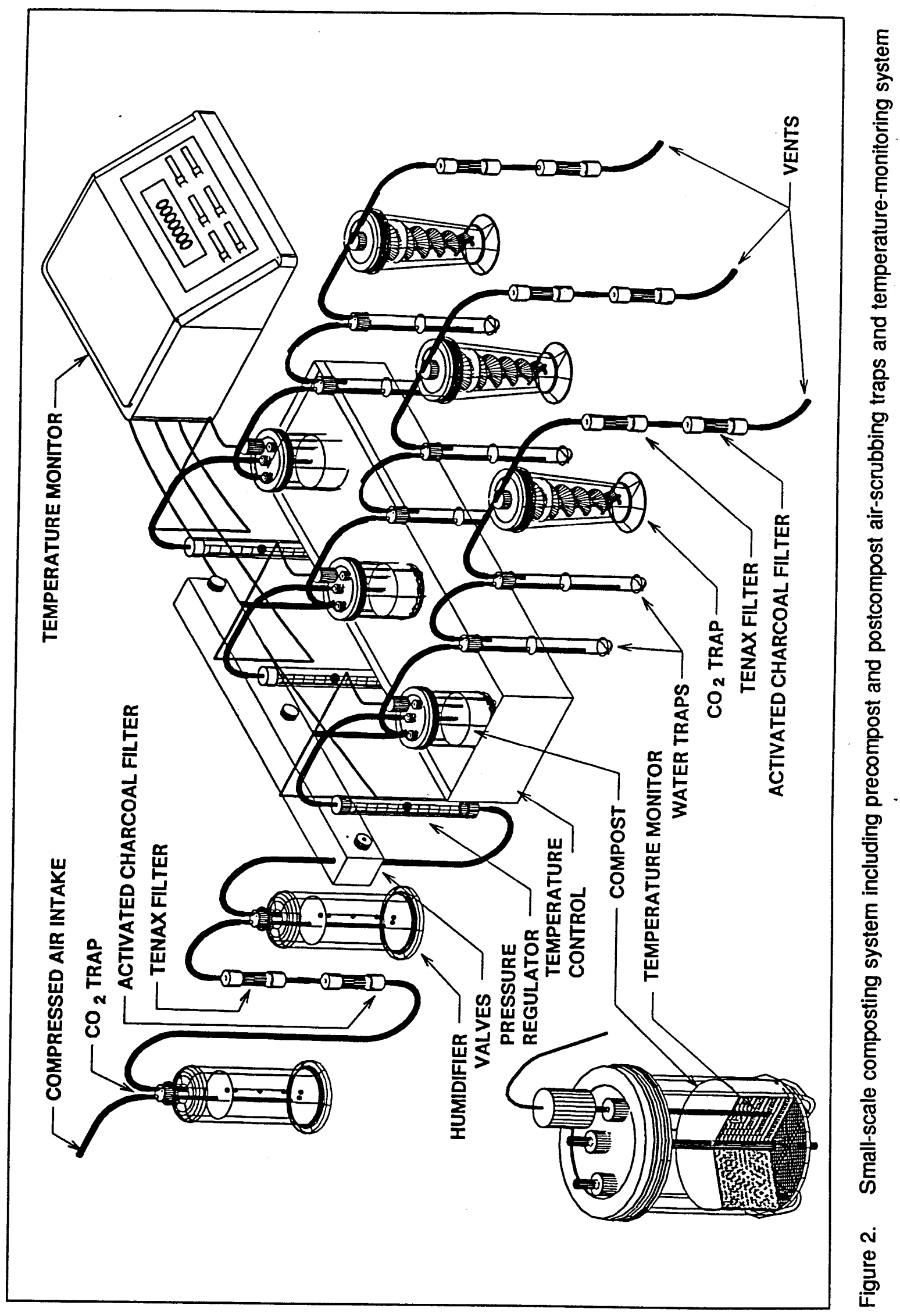




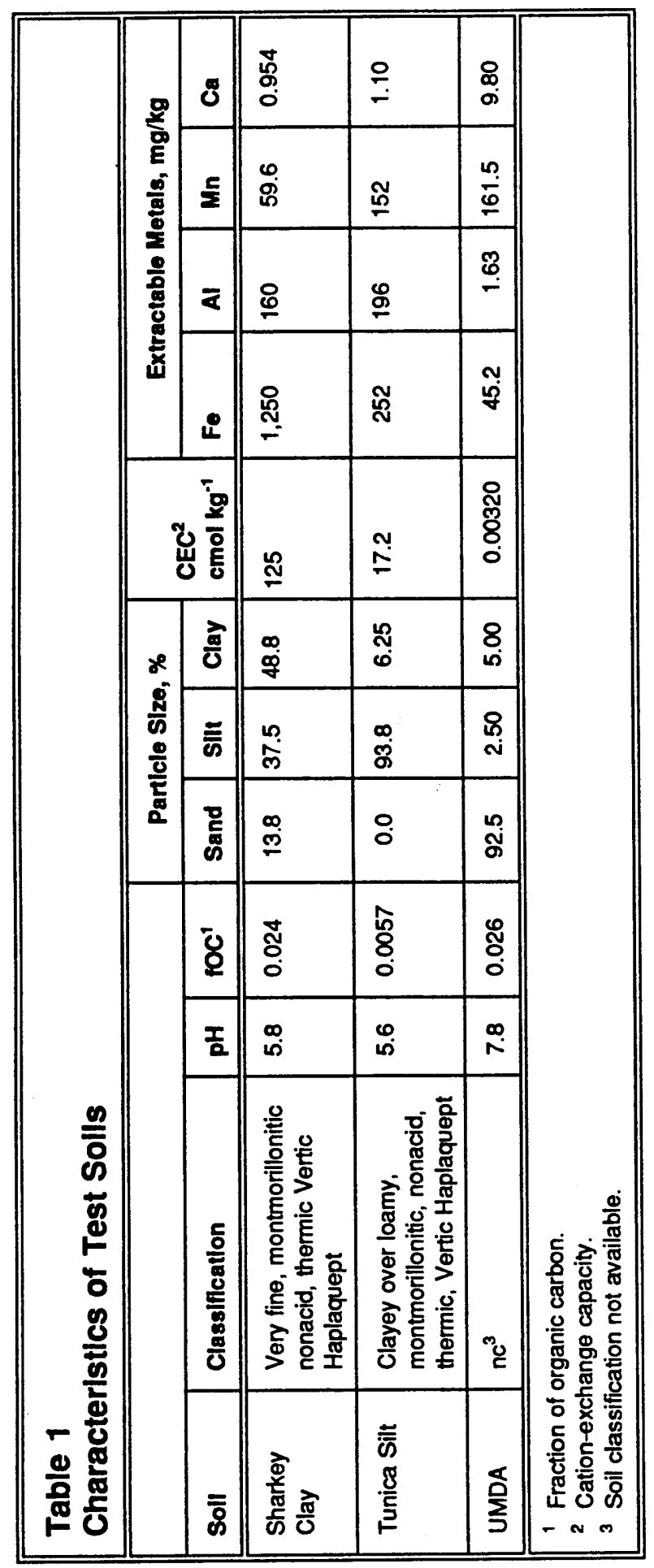

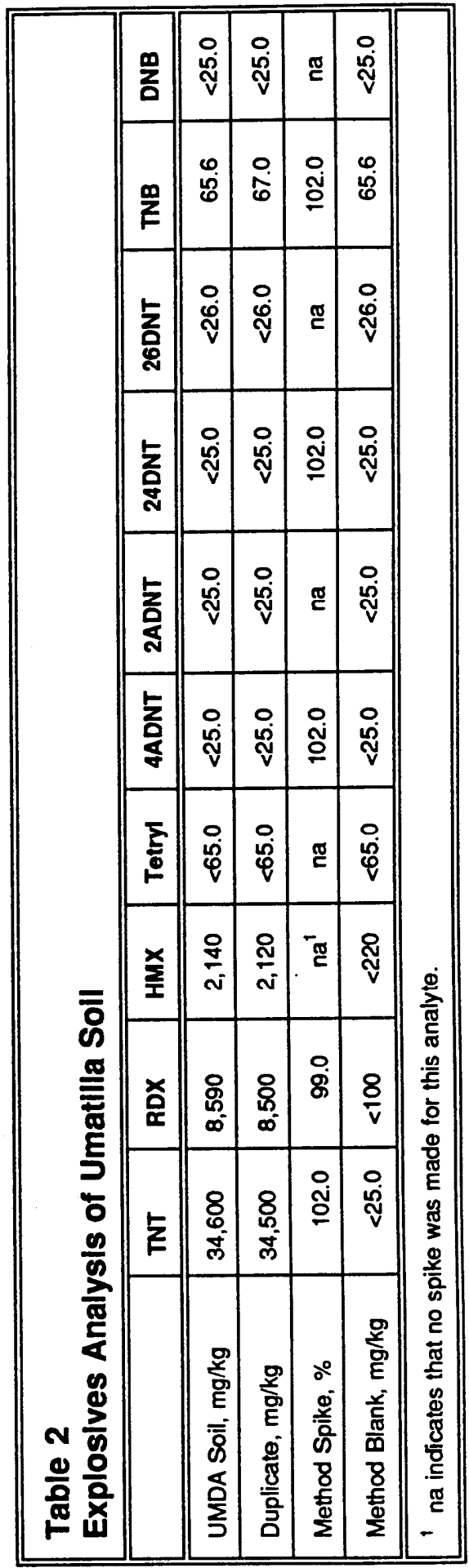


1,3,5-trinitrobenzene (TNB), 2,4-dinitrotoluene (24DNT), 2,6-dinitrotoluene (26DNT), 2-amino-4,6-dinitrotoluene (2ADNT), 2,4-dinitrobenzene (DNB), and 4-amino-2,6-dinitrotoluene (4ADNT). Sharkey clay and Tunica silt, which were taken from sites having no history of exposure to explosives, were not analyzed for explosives.

\section{Soll amendment for Experiment I}

Soils were amended with 10- $\mu$ g TNT/g ODW of soil. One-tenth of the amendment $\left(1-\mu \mathrm{g}\right.$ TNT/g) was [U-ring $-{ }^{14} \mathrm{C}_{\mathrm{TNT}}{ }^{1}\left(2.1 \times 10^{5} \mathrm{DPM}\right.$ (disintegrations per minute)/g ODW). Sufficient water was added to $237 \mathrm{~g}$ (ODW) of clay and $240 \mathrm{~g}$ (ODW) of silt to produce a 1:2 soil:water ratio. A methanol solution containing the radiolabeled and unlabeled TNT was added. The resulting slurries were then placed on a reciprocating box shaker (Eberbach Corporation, Ann Arbor, MI) for $24 \mathrm{hr}$ at 280 excursions per minute to allow partitioning of contaminant into the aqueous and solid phases. Results of kinetic studies conducted previously indicated that $24 \mathrm{hr}$ was sufficient to develop steady-state conditions (Pennington and Patrick 1990). The soil slurries were air dried under a radiological safety hood for $72 \mathrm{hr}$, then ground to pass through a 2-mm sieve. Amended soils were mixed with other compost components (see Compost Composition below) and added to individual reactors. Two reactors received TNT-amended silt and two received TNTamended clay. The compost contained 0.9- $\mu \mathrm{g}$ TNT/g ODW and $1.8 \times 10^{4}$ DPM/g ODW. One reactor received silt without TNT and one clay without TNT to serve as untreated controls. These reactors provided compost material for background determinations in the analytical processes and for determining any effects of TNT on operational parameters such as total $\mathrm{CO}_{2}$ and microbial populations.

\section{Soll amendment for Experiments II and III}

Because of problems with recoveries from Experiment I, the partitioning method was slightly modified. The vigor of the shaking was reduced by using a rotatory shaker, and the time of shaking was reduced to $4 \mathrm{hr}$. Recent research by Brannon (unpublished) indicates that vigorous, longer shaking results in greater transformation of TNT. Soils were amended with 100- $\mu$ g cold TNT and $250-\mu \mathrm{g}$ radiolabeled TNT $^{2}$ per g ODW $\left(1.0 \times 10^{7} \mathrm{DPM} / \mathrm{g}\right)$ by directly spiking an aqueous slurry of soil in a rotatory shaker (New Brunswick Scientific, New Brunswick, NJ) at 112 rotations per minute for $4 \mathrm{hr}$ at $4{ }^{\circ} \mathrm{C}$. The $4 \mathrm{hr}$ was still within steady-state limits according to kinetics studies

1 New England Nuclear Research Products, Boston, MA. Specific activity of $20 \mathrm{mCi} / \mathrm{mmol}$; radiological purity $>98$ percent by HPLC with radiation detector; chemical purity $>98$ percent by HPLC with an ultraviolet detector.

2 Specific activity of $4.12 \mathrm{mCi} / \mathrm{mmol}$; radiological purity $>97.9$ percent by thin-layer chromatography; chemical purity $>99$ percent by HPLC with an ultraviolet detector. 
(Pennington and Patrick 1990). Each slurry was transferred to individual batches of compost in a single reactor. This resulted in compost concentrations of 31.82- $\mu \mathrm{g}$ TNT per $\mathrm{g}$ ODW $\left(1.0 \times 10^{6} \mathrm{DPM} / \mathrm{g}\right)$. Two reactors received TNT-amended silt and two received TNT-amended clay. One reactor received unamended silt and one received unamended clay to serve as untreated controls.

\section{Soil amendment for Experiment IV}

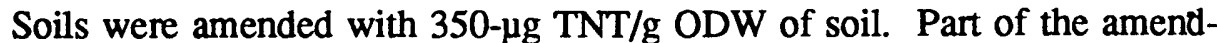
ment $(250 \mu \mathrm{g} / \mathrm{g})$ was [U-ring- $\left.{ }^{14} \mathrm{C}\right] \mathrm{TNT}^{1}\left(1.0 \times 10^{7} \mathrm{DPM} / \mathrm{g}\right.$ ODW $)$. The remainder was unradiolabeled TNT. Sufficient water was added to $4.74 \mathrm{~g}$ (ODW) of clay and $4.81 \mathrm{~g}$ (ODW) of silt to produce a 1:4 soil:water ratio for each compost reactor. A methanol solution containing the radiolabeled and unlabeled TNT was added. The resulting slurries were placed on a rotating shaker (New Brunswick Scientific, New Brunswick, NJ) at 400 rotations per minute for $4 \mathrm{hr}$ at $4{ }^{\circ} \mathrm{C}$ to allow partitioning of contaminant into the aqueous and solid phases. Soil slurries were mixed with other compost components (see Compost Composition below) and added to individual reactors. Two reactors received TNT-amended silt and two received TNT-amended clay. The final compost contained 15.5- $\mu \mathrm{g}$ TNT/g ODW and $3.5 \times 10^{5} \mathrm{DPM} / \mathrm{g}$ ODW. Two reactors, one of silt and one of clay, were unamended to serve as controls.

\section{Soll amendment for Experiments V and VI}

The UMDA soil was amended with $350-\mu$ g radiolabeled TNT $^{2}$ per $\mathrm{g}$ ODW $\left(9.0 \times 10^{7} \mathrm{DPM} / \mathrm{g}\right)$ by directly spiking an aqueous slurry of soil in a rotatory shaker as described for Experiment IV. This resulted in a total TNT concentration in the UMDA soil of $34,900 \mu \mathrm{g} / \mathrm{g}$. Each slurry was transferred to individual batches of compost in a single reactor. Since UMDA soil was contaminated with $34,550-\mu \mathrm{g}$ TNT/g, the amendment resulted in a compost

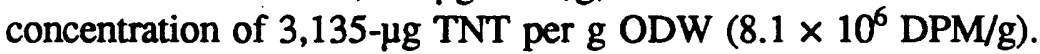

For Experiment V, compost and soil for two of the reactors were sterilized by autoclaving at $121^{\circ} \mathrm{C}$ and $15 \mathrm{lbf}^{3}$ of pressure for $1 \mathrm{hr}$. Filter-sterilized radiolabeled TNT was added aseptically to sterilized soils, and the amended soils were mixed with the sterilized compost. Two other reactors received sterilized compost plus an inoculum of one-third unautoclaved compost. Two reactors were unautoclaved.

1 Specific activity of $4.12 \mathrm{mCi} / \mathrm{mmol}$; radiological purity $>97.9$ percent by thin-layer chromatography; chemical purity $>99$ percent by HPLC with an ultraviolet detector.

2 Specific activity of $11.0 \mathrm{mCi} / \mathrm{mmol}$; radiological purity $>99$ percent by thin-layer chromatography; chemical purity $>99$ percent by HPLC with an ultraviolet detector.

3 To convert pounds (force) to newtons, multiply by 4.448222 . 


\section{Compost Composition}

The compost mixture for all experiments consisted of 33 percent green cow manure, 22 percent sawdust, 6.0 percent chopped apples, 17 percent chopped potatoes, and 22 percent alfalfa. All components were added as percent of wet weight. Ten percent soil was also added to the compost mixture. All amendments were of particle size $10 \mathrm{~mm}$ or less. Finer amendments were mixed first; successively larger particle-sized amendments were added as mixing continued. Chopping and mixing were done by hand. The final mixture was moistened to 60 percent water by weight. Compost for each reactor was prepared separately.

\section{Airflow}

Compressed air was supplied to the system at $10 \mathrm{~mL} / \mathrm{min}$. Volatile compounds and $\mathrm{CO}_{2}$ were scrubbed from the air by passing it through a $5 \mathrm{~N} \mathrm{KOH}$ trap followed by successive traps containing tenax and activated charcoal (Figure 2). For Experiment II, air passing into sterilized reactors was also passed through a bacterial air filter (Gelman Sciences, Ann Arbor, MI). Air was humidified by passage through sterile water and subsequently distributed via manifolds connected to flow meters that fed the individual reactors. The air was delivered below the false floor where it passed up through the compost mixture and out the exit port. Upon exiting the compost mixture, the air passed through traps containing $5 \mathrm{~N} \mathrm{KOH}$, tenax, and charcoal to collect any $\mathrm{CO}_{2}$ and VOCs produced during composting. Air exiting the last trap was vented through a radiation safety hood. The $\mathrm{CO}_{2}$ traps were changed and assayed daily; all other traps were changed weekly.

\section{Incubation}

The water bath for Experiments I, II, III, and V was maintained at $30^{\circ} \mathrm{C}$. Mesophilic conditions were selected for these experiments to determine the effects of mesophilic processes on the fate of TNT in the compost without additional heat, which is known to affect the stability of TNT.

Incubation of compost reactors for Experiments IV and VI was carried out in a water bath maintained at $55^{\circ} \mathrm{C}$ to determine the effects of thermophilic processes on TNT fate. 


\section{Monitoring}

\section{Temperature}

Temperature was monitored via a Scanning Thermocouple Thermometer (Cole-Palmer Instrument Company, Chicago, IL) positioned in the center of each compost reactor. Temperature was recorded automatically every $30 \mathrm{~min}$, and the daily mean, maximum, and minimum temperatures determined.

\section{Total and radiolabeled $\mathrm{CO}_{2}$}

Total $\mathrm{CO}_{2}$ was monitored daily by titration. A $2-\mathrm{mL}$ aliquot of $5 \mathrm{~N} \mathrm{KOH}$ trapping solution was added to $25 \mathrm{~mL}$ of $\mathrm{CO}_{2}$-free water and $5 \mathrm{~mL}$ of $2 \mathrm{~N}$ $\mathrm{BaCl}_{2}$ and titrated with $0.5 \mathrm{~N} \mathrm{HCl}$ to a clear phenolphthalein end point. The $5 \mathrm{~N} \mathrm{KOH}$ was standardized against $10 \mathrm{~g}$ of primary standard $\mathrm{KHC}_{8} \mathrm{H}_{4} \mathrm{O}_{4}$ (potassium hydrogen phthalate); the $\mathrm{HCl}$ was standardized against the standard $\mathrm{KOH}$. The above titration was performed before and after trapping to determine the total $\mathrm{CO}_{2}$ by difference. Radiolabeled $\mathrm{CO}_{2}$ was determined by counting $0.5 \mathrm{~mL}$ of $\mathrm{KOH}$ with $2.5 \mathrm{~mL}$ water and $15 \mathrm{~mL}$ of Ultima Gold Liquid Scintillation Cocktail (Packard Instruments, Meridan, CT) on a Packard Tricarb 2500 TR Liquid Scintillation (LS) Counter (Packard Instruments, Meridan, CT).

\section{VOCs}

All intake and exit traps (tenax and charcoal) were changed weekly. Exit traps were extracted with $5 \mathrm{~mL}$ of methanol in sealed containers and sonicated for $12 \mathrm{hr}, 1 \mathrm{~mL}$ of the extract was counted by LS.

\section{Microorganisms}

Microorganisms were monitored at $0,1,5,10,15$, and 20 days in Experiments I (in clay reactor only), II, and IV; at 0,10, and 20 days in Experiments V and VI; and at 0 and 20 days only in Experiment III. Dry weights were determined at the time of microbial sampling by drying $1 \mathrm{~g}$ wet weight in a $60^{\circ} \mathrm{C}$ oven for $48 \mathrm{hr}$.

Microbial biomass was estimated using direct plate counts. Serial dilutions of compost $\left(10^{-2}\right.$ through $\left.10^{-7}\right)$ were plated onto 5 percent peptone, tryptone, yeast extract, glucose agar (PTYG) with pH adjusted to 6.8 (Table 3) using standard microbiological techniques. Mesophilic cultures were incubated at $30^{\circ} \mathrm{C}$ and thermophilic at $60^{\circ} \mathrm{C}$ for 2 to 3 weeks. 


\begin{tabular}{|l|l|}
\hline $\begin{array}{l}\text { Table 3 } \\
\text { Composition of Peptone, Tryptone, Yeast Extract, Glucose } \\
\text { Medlum }\end{array}$ \\
\hline \hline Component & $\mathrm{g} / \mathrm{L}$ \\
\hline \hline Peptone & 0.25 \\
\hline Tryptone & 0.25 \\
\hline Yeast extract & 0.5 \\
\hline D-glucose & 0.5 \\
\hline $\mathrm{MgSO}_{4} \cdot 7 \mathrm{H}_{2} \mathrm{O}$ & 0.6 \\
\hline $\mathrm{CaCl}_{2} \cdot 2 \mathrm{H}_{2} \mathrm{O}$ & 0.07 \\
\hline $\mathrm{KCl}$ & 2.0 \\
\hline Gelrite & 10.0 \\
\hline
\end{tabular}

\section{Analysis of Compost}

\section{Bulk density}

Bulk density was measured at the beginning and end of each experiment except for Experiment I. Determinations were made by measuring the volume of an equivalent depth of water in the reactor (less the false floor volume) and determining ODW of the compost.

\section{Fractionation}

Solvent extraction series: Experiment IV. The compost fractionation scheme for Experiment IV began with a solvent extraction to remove soluble, unbound explosives residue and transformation products (Figure 3). Three solvents (ether, acetone, and acetonitrile) were chosen to encompass a broad range of polarities, i.e., the ether is a nonpolar solvent, acetonitrile is polar, and acetone is intermediate between the two. After subsampling for moisture content, the compost samples were transferred to preweighed 200 -mL glass centrifuge bottles. Each centrifuge bottle was reweighed and the total amount of compost in each extraction calculated. The extraction sequence consisted of consecutive 18-hr extractions on a reciprocating shaker, followed by centrifugation for $30 \mathrm{~min}$ at 2,000 RCF. Each sample was extracted twice with $50 \mathrm{~mL}$ of ether, twice with $50 \mathrm{~mL}$ of acetone, followed by two $40-\mathrm{mL}$ extractions with acetonitrile. The supernate from each of the two extractions with the same solvent was combined. Three $1-\mathrm{mL}$ portions of each solvent fraction were counted for each sample. The compost was extracted wet, but was allowed to dry slightly between additions of different solvents. 


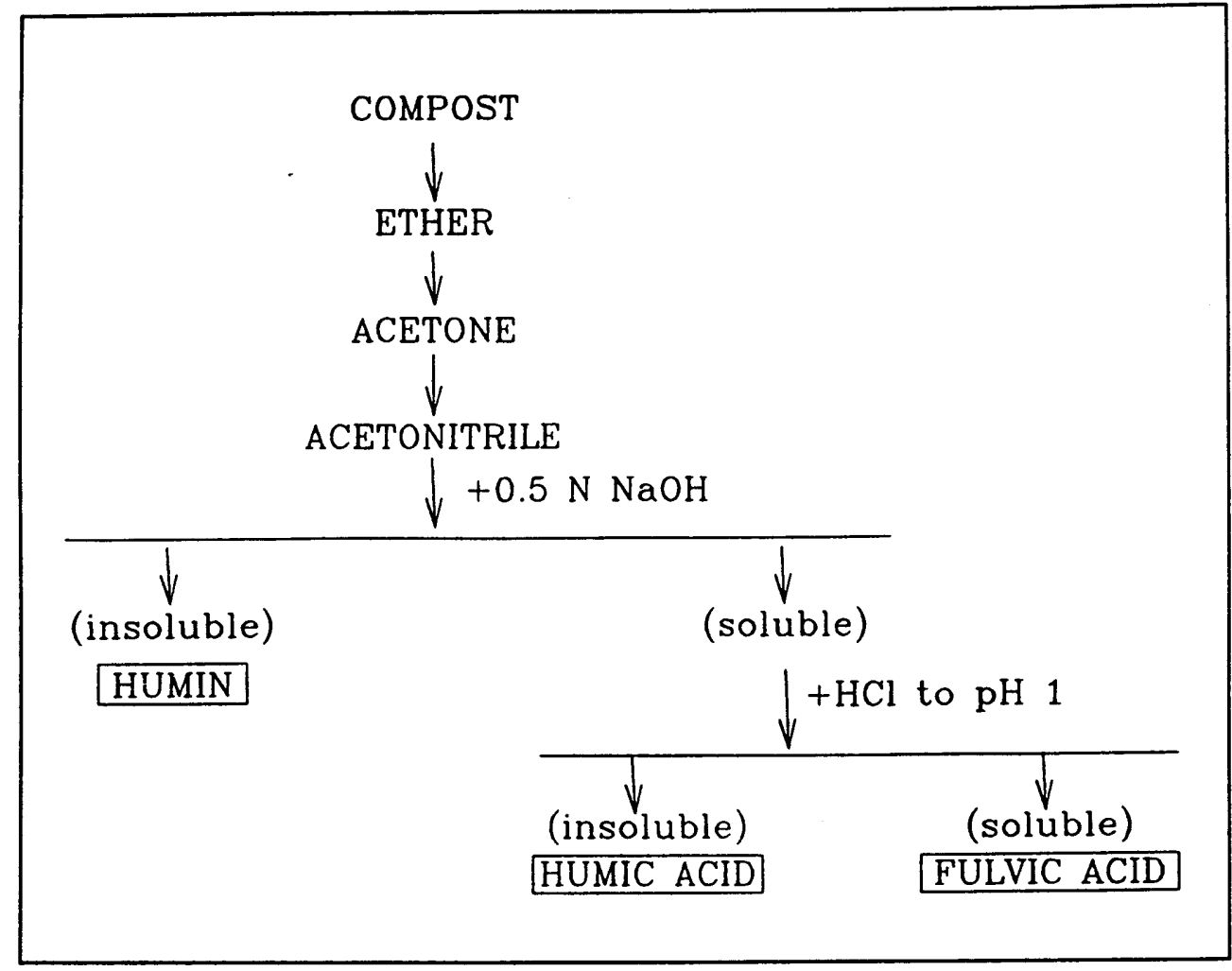

Figure 3. Extraction and fractionation scheme for composted material in Experiment IV. Fractions were assayed by liquid scintillation counting

Solvent extraction series: Experiments V and VI. In Experiments V and VI, acetone was eliminated from the extraction scheme (Figures 4 and 5) because the extracts were colored, which is an indication of stripping of humic compounds. The compost was sampled and extracted as described previously with two 50-mL extractions each of ether, followed by acetonitrile.

Organic matter fractionation: Experiment IV. The organic matter fractionation procedure was adapted from Stevenson (1989) (Figure 3). After air drying, the material remaining from the final acetonitrile extraction was reextracted with $50 \mathrm{~mL}$ of $0.5 \mathrm{~N} \mathrm{NaOH}$ for $18 \mathrm{hr}$. Following phase separation by centrifugation, the supernate was removed to a second centrifuge bottle. The remaining insoluble material was reextracted in an additional $50 \mathrm{~mL}$ of $0.5 \mathrm{~N} \mathrm{NaOH}$ for $4 \mathrm{hr}$. The supernate was combined with the first $50 \mathrm{~mL}$. The insoluble material was washed in $50 \mathrm{~mL}$ of Milli-Q water by shaking for $1 \mathrm{hr}$. Before the final centrifugation, the sides of the bottle were rinsed with $10 \mathrm{~mL}$ of Milli-Q water. The supernate from this rinse was also added to the $\mathrm{NaOH}$ solution. The insoluble material remaining after the $\mathrm{NaOH}$ fractionation contained the humin fraction as well as remaining cellulose. This material was well mixed, subsampled for percent solids determination, and subjected to complete combustion analysis. The $\mathrm{NaOH}$ solution was acidified with 50-percent $\mathrm{HCl}$ to a $\mathrm{pH}$ of 1 and allowed to settle overnight. After 


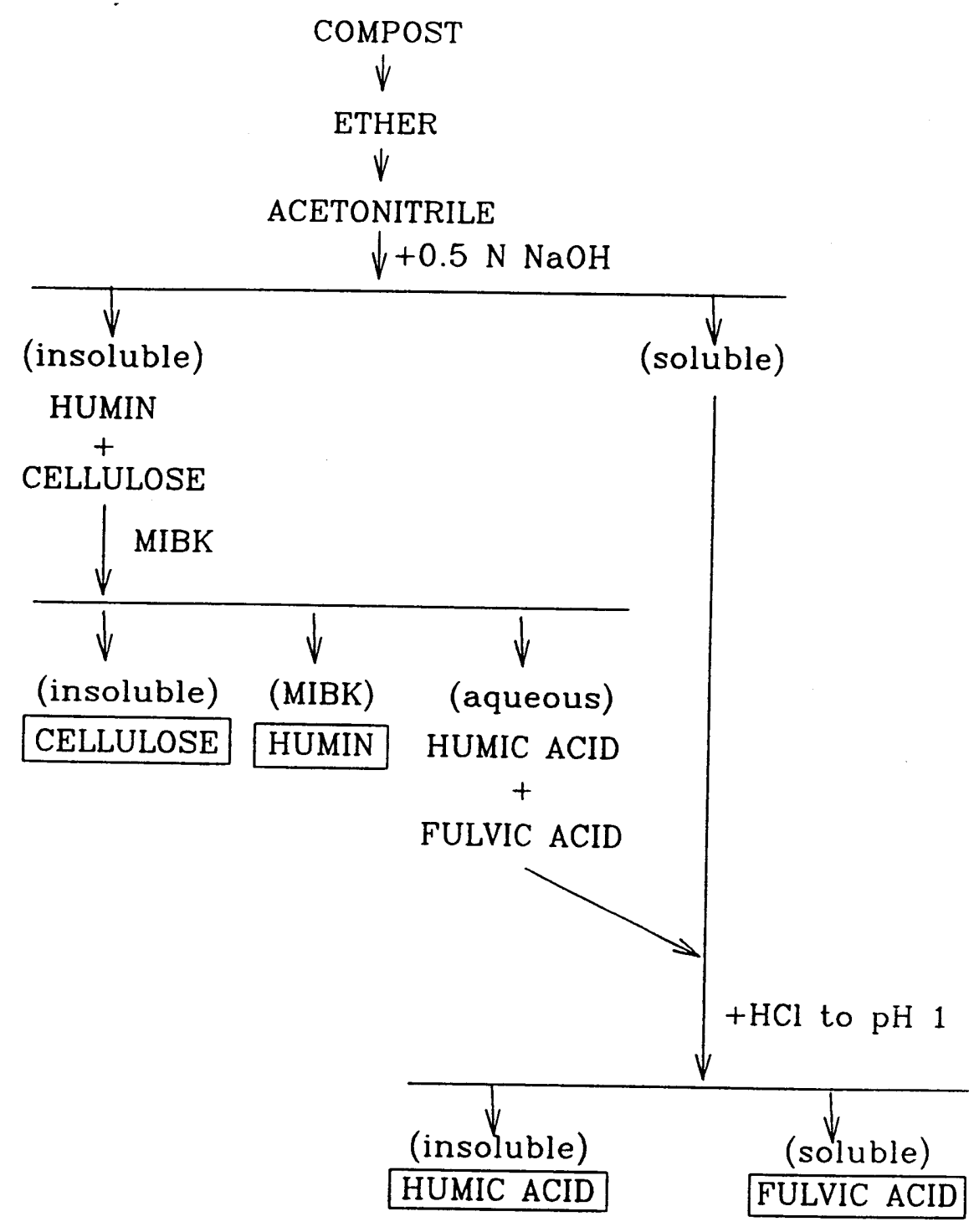

Figure 4. Extraction and fractionation scheme for composted material in Experiment V. Fractions were assayed by liquid scintillation counting

centrifugation to separate phases, the supernate containing the soluble fulvic acid was removed. Three $1-\mathrm{mL}$ portions of fulvic acid solution were counted by LS. The insoluble humic acid remaining in the centrifuge bottle was 


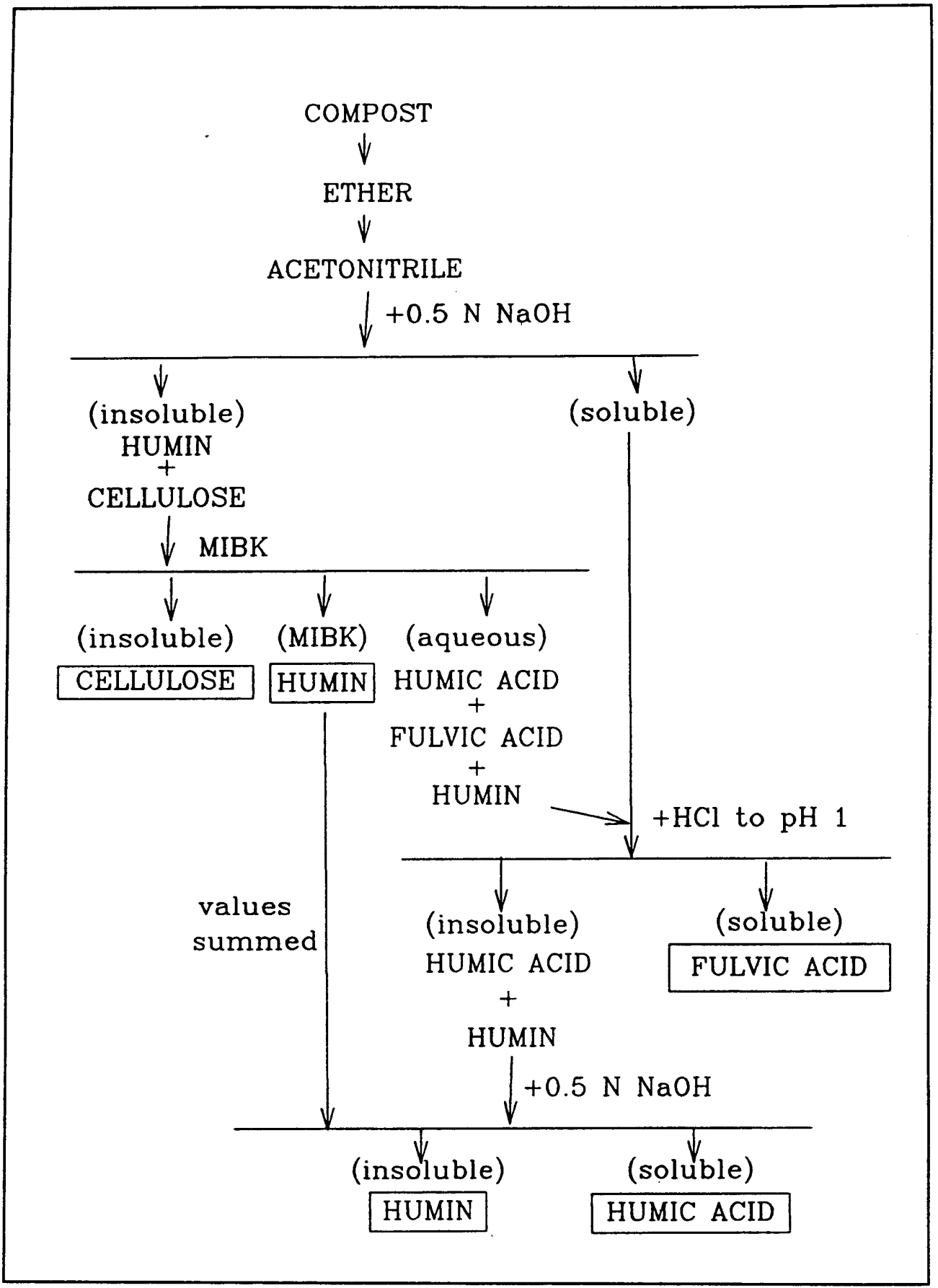

Figure 5. Extraction and fractionation scheme for composted material in Experiment VI. Fractions were assayed by liquid scintillation counting

subjected to complete combustion analysis after subsampling for percent solids determination.

Organic matter fractionation: Experiment V. The procedure for fractionation of organic matter for Experiment $\mathrm{V}$ follows that given above for 
Experiment IV for obtaining the humin, humic, and fulvic acid fractions. However, the humin fraction was further fractionated to separate the cellulose from the true humin material (Figure 4). The residue remaining after extraction with $\mathrm{NaOH}$ consisted of the cellulose and humin fractions in an aqueous matrix. This material was extracted with $40 \mathrm{~mL}$ of methylisobutylketone (MIBK) according to the method of Rice and MacCarthy (1989). By this method, the MIBK phase should contain the humin fraction in suspension. This extraction caused the MIBK to replace water as the wetting agent for the cellulose and resulted in the following three-phase separation: a slightly colored organic phase (humin in MIBK), an aqueous phase, and an insoluble phase (cellulose). The aqueous phase was removed and added to the $\mathrm{NaOH}$ soluble material from the previous extraction. Three 1-mL portions of each MIBK/humin sample were counted by LS. The cellulose fraction remaining was well mixed, subsampled for moisture determination, and subjected to complete combustion analysis.

The $\mathrm{NaOH}$ soluble material was acidified as described for Experiment I to separate the humic and fulvic acids. The insoluble humic acid was redissolved in $\mathrm{NaOH}$ and acidified once more to remove any remaining fulvic acid. Three 1-mL portions of the combined fulvic acid fraction were counted by LS. The humic acid was redissolved in $20 \mathrm{~mL} \mathrm{NaOH}$ and well mixed to ensure complete dissolution. Three 1-mL portions of each sample were counted by LS.

Organic matter fractionation: Experiment VI. The procedure for fractionation of organic matter for Experiment VI followed that given above for Experiment $\mathrm{V}$ through the separation and removal of the acidified fulvic acid phase from the insoluble humic acid phase. This insoluble phase was determined to contain both humic acid and humin (Figure 5). An additional separation was accomplished by completely redissolving the humic acid in $15 \mathrm{~mL}$ $0.5 \mathrm{~N} \mathrm{NaOH}$, centrifuging to separate phases and removing the $\mathrm{NaOH}$-soluble humic acid fraction. This process was repeated by reextracting the insoluble pellet with an additional $10 \mathrm{~mL}$ of $0.5 \mathrm{~N} \mathrm{NaOH}$. The resulting supernate was combined with the first humic acid extract. Three 1-mL portions of each humic acid fraction were counted by LS. The insoluble material remaining contained most of the humin fraction. The fraction was analyzed by complete combustion and/or by suspending the particles in gelled liquid scintillation cocktail.

\section{Radioactivity}

Radioactivity in the compost was measured by complete combustion of two replicate samples of $0.10 \mathrm{~g}$, wet weight (or 0.02 to $0.05 \mathrm{~g} \mathrm{ODW}$ ) compost in a Model 307 Packard Sample Oxidizer (Packard Instruments, Meridan, CT). Oxidized carbon was trapped as $\mathrm{CO}_{2}$ in Carbo-Sorb and Permaflour Liquid Scintillation Cocktail (Packard Instruments, Meridan, CT) and assayed by LS counting on a model 2500TR Liquid Scintillation Counter (Packard Instruments, Meridan, CT). Samples were analyzed at 20 days for 
Experiments I and II, at 0 and 20 days for Experiments III and IV, and at 0 , 10 , and 20 days for Experiments V and VI.

\section{High performance liquid chromatography (HPLC)}

HPLC for all experiments. Compost samples were analyzed for the following analytes: TNT, 4ADNT, 2ADNT, 24DNT, 26DNT, 24DANT, 26DANT, TNB, and DNB according to the method for soil described in EPA SW-846 Method 8330 (EPA 1990). The HPLC system consisted of a 600E system controller, a 712 Wisp Auto Injector, and a 486 Tunable Absorbance Detector (Waters Associates, Inc., Milford, MA). The compost extracts were analyzed on an Ultracarb 5 octadecylsilane (ods) $20(250 \times 3.2 \mathrm{~mm})$ column (Phenomenex, Torrance, CA) eluted with 1:1 methanol/water at $0.5 \mathrm{~mL} / \mathrm{min}$. 


\section{Results and Discussion}

\section{Experiment I}

\section{Small-scale reactor performance}

Experiment I was intended as a developmental exercise for designing and testing various components of the test system and for development and refinements in analytical techniques. Results of temperature, $\mathrm{CO}_{2}$ evolution, and microbial counts (Figures 6-8) were consistent with expected values. Internal compost temperature was maintained at a mean of $29 \pm 2{ }^{\circ} \mathrm{C}$ (Figure 6). Temperature drops of 10 to $15^{\circ} \mathrm{C}$, which are evident on the graphs when vessels were opened (Figure 6), were attributed to disturbance of the thermistors. Recovery was rapid once the test chambers were reassembled. Improvements in sampling procedures eliminated this temperature artifact in subsequent experiments.

Carbon dioxide evolving from the reactors fluctuated widely throughout the 20-day study (Figure 7). Some of the variability is attributable to opening reactors for sampling on days $1,5,10$, and 15 . However, some reactors also developed leaks and other problems that required opening the reactors at times other than the sampling periods. Subsequent experiments in which such problems were remedied exhibited dramatic reductions in total $\mathrm{CO}_{2}$ evolved. The quantity of $\mathrm{CO}_{2}$ was also more consistent and variability was reduced.

Total microorganisms as determined by direct plate counts increased from $1.4 \times 10^{8}$ colony forming units (CFUs)/g at $\mathrm{T}_{0}$ to $2.34 \times 10^{10} \mathrm{CFUs} / \mathrm{g}$ at $\mathrm{T}_{5}$ (Figure 8). Populations declined gradually after the fifth day until near original $\left(T_{0}\right)$ values were reached by day 20 .

\section{Analysis of solls}

Radioassays of amended soils before composting yielded only 31 and 29 percent recovery for the clay and silt, respectively. Subsequent experiments in which the soil amendment and oxidation methods were modified resulted in improved recoveries. (See Experiment III results.) 

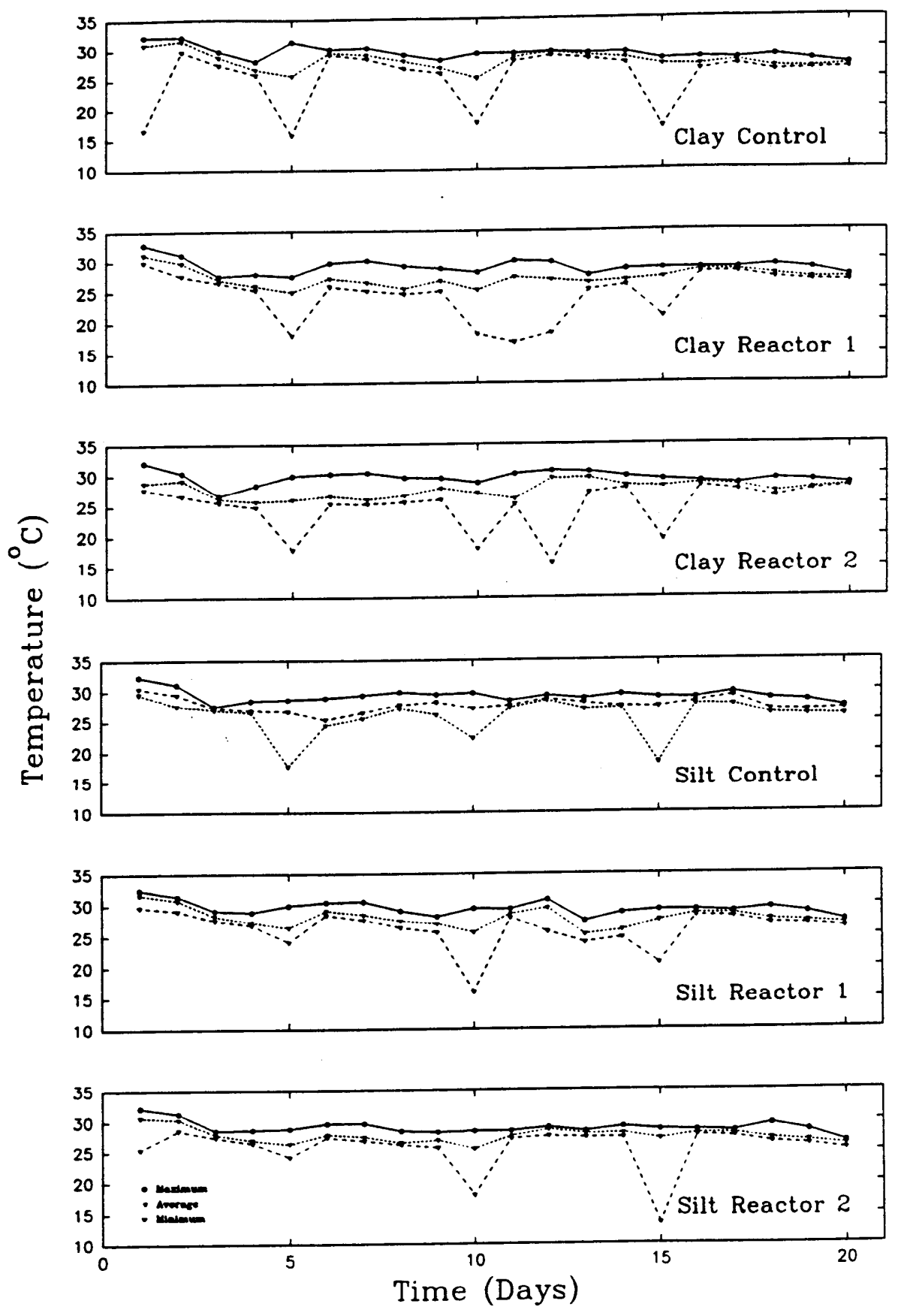

Figure 6. Mean daily maximum, average, and minimum temperatures in composted clay and silt reactors from Experiment $\mathrm{I}$. Each datum point represents average of all 30-min readings recorded in each $24-\mathrm{hr}$ period. Controls received no TNT 


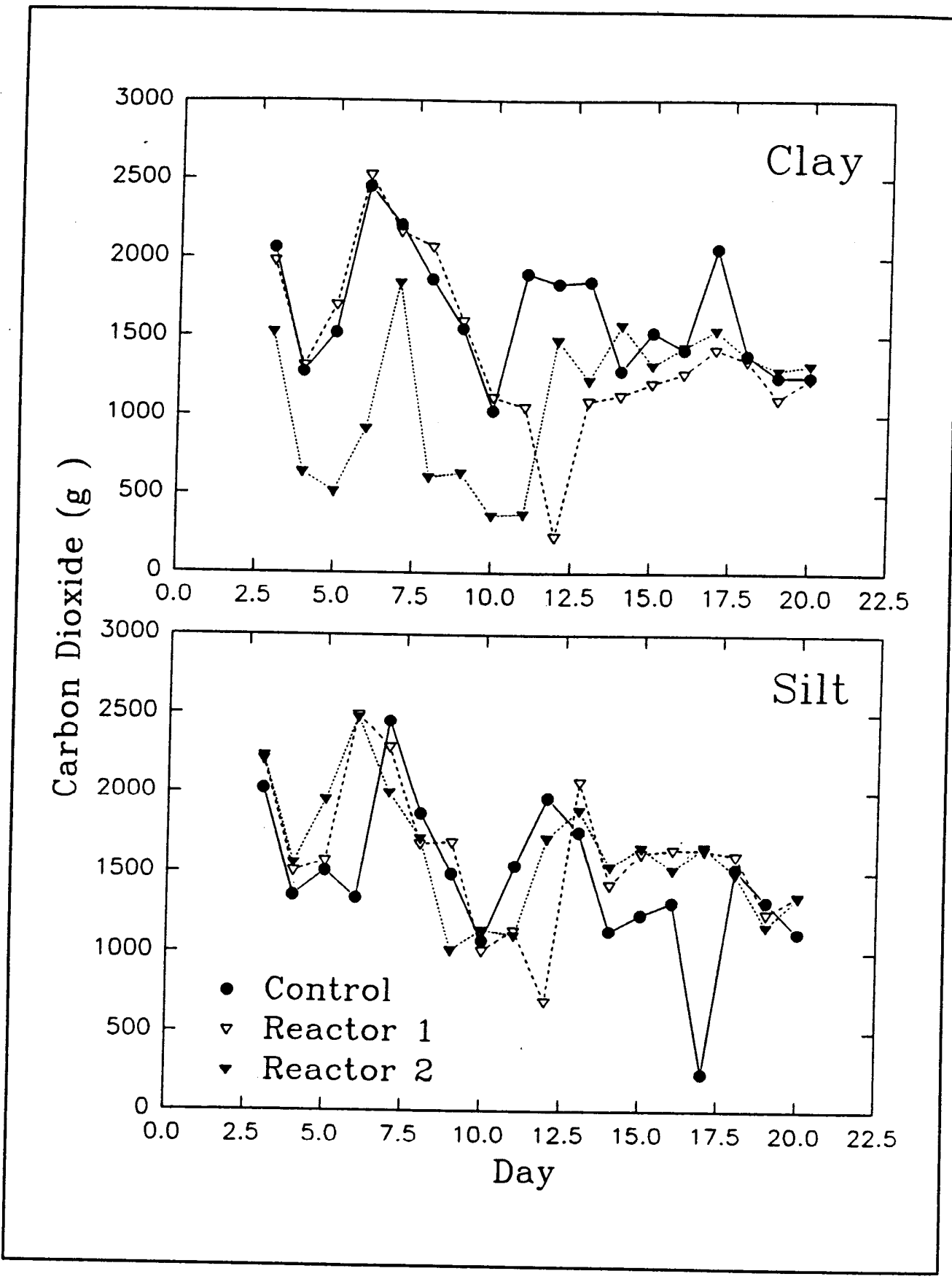

Figure 7. Daily total carbon dioxide evolved from each reactor from Experiment I. Each datum point represents sum of two traps in series

\section{Analysis of compost}

Complete combustion. Complete combustion analysis of the unextracted compost yielded 53-percent recovery of the radiolabel from composted clay and 36 percent from composted silt (Table 4). These values represent not only recoveries from the combined unextractable and extractable compost, but also 


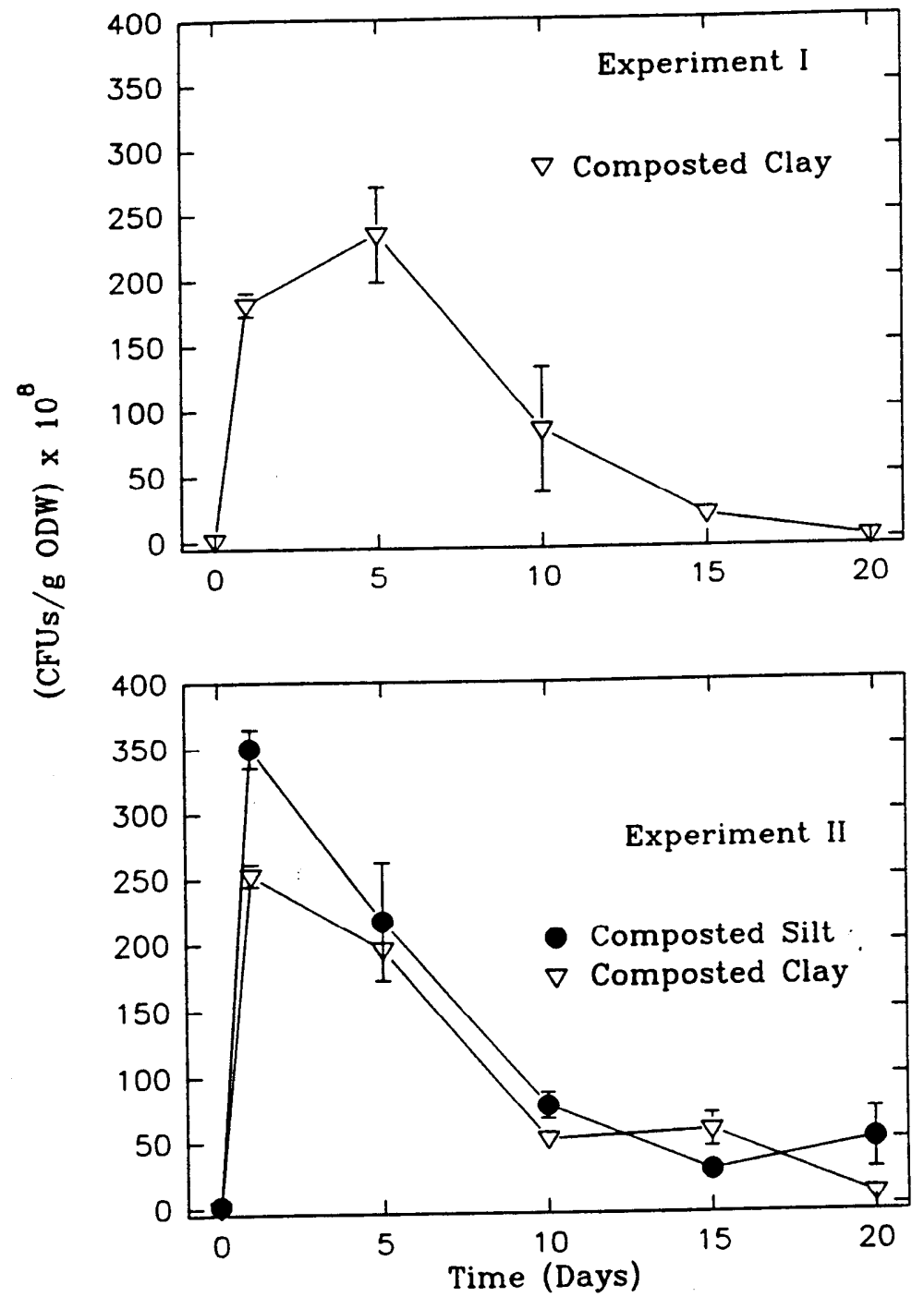

Figure 8. Microbial populations as determined by direct plate counts of composted clay and silt from Experiments I and II. Each datum point represents mean of three plate counts of a dilution exhibiting 30 to $300 \mathrm{CFUs} / \mathrm{g}$ of compost (ODW). Vertical bars are standard errors of mean 


\begin{tabular}{|c|c|c|c|c|c|}
\hline \multicolumn{6}{|c|}{$\begin{array}{l}\text { Table } 4 \\
\text { Percent Recoveries of Radiolabel from All Compartments in } \\
\text { Experiment I }\end{array}$} \\
\hline \multirow[b]{2}{*}{ Treatment } & \multicolumn{2}{|c|}{ Compost } & \multirow[b]{2}{*}{ Vocs } & \multirow[b]{2}{*}{$\mathrm{CO}_{2}$} & \multirow[b]{2}{*}{ Total' } \\
\hline & Combustion & HPLC/Radio & & & \\
\hline Clay control & $\mathrm{ND}^{2}$ & ND & ND & ND & ND \\
\hline Clay TNT 1 & 52.68 & ND & ND & ND & 52.68 \\
\hline Clay TNT 2 & 53.24 & ND & ND & ND & 53.24 \\
\hline Silt $\infty$ ntrol & ND & ND & ND & ND & ND \\
\hline Silt TNT 1 & 33.79 & ND & ND & ND & 33.79 \\
\hline Silt TNT 2 & 38.66 & ND & ND & ND & 38.66 \\
\hline
\end{tabular}

total percent recoveries since no radiolabel was recovered from the VOC or $\mathrm{CO}_{2}$ compartments. Therefore, the error term in this mass balance is high, 47 and 64 percent for composted clay and silt, respectively. The large error was postulated to be due to the amendment technique used to introduce TNT into the soils and inadequate oxidation efficiency with the sample oxidizer. The soils were amended in a slurry that was subsequently air dried in a thin layer under a fume hood. This process may have resulted in loss of significant quantities of the radiolabeled material as either volatile decomposition products or through fine particles blown off the soil surface by the forced air of the hood. Oxidation of soils containing organic carbon (OC) tends to be more efficient than oxidation of soils containing little $\mathrm{OC}$. The recoveries from compost followed the same trend, i.e., recoveries from compost containing the higher OC soil (clay) were higher than recoveries from compost containing the lower OC soil (silt).

HPLC analysis. Compost material subjected to HPLC analysis yielded no detectable concentrations of TNT, nor transformation products, and no radiolabeled peaks. Lack of detection by ultraviolet (UV) fluorescence is attributable to (a) lack of extractability of the transformed parent compound and/or (b) very low TNT concentrations in the tests. The detection limit with the UV detector $(0.25 \mu \mathrm{g}$-TNT/g ODW compost) was exceeded by the test concentration (1 $\mu \mathrm{g}-\mathrm{TNT} / \mathrm{g}$ ODW compost). Therefore, lack of detection is more likely due to lack of extractability.

\section{VOCs and $\mathrm{CO}_{2}$}

No radiolabeled VOCs nor $\mathrm{CO}_{2}$ were detected. Low treatment level and frequent opening of vessels may explain this result since ${ }^{14} \mathrm{CO}_{2}$ in very small 
quantities was detected in subsequent experiments. However, no radiolabeled VOCs were detected in any subsequent experiments in the tenax nor the activated charcoal traps.

\section{Experiment II}

Although the objective of Experiment II was to evaluate microbial behavior of the compost system and to refine microbial monitoring procedures, the experiment also allowed validation of the modifications identified by Experiment I. For example, concentrations and variability in $\mathrm{CO}_{2}$ data were dramatically reduced (Figure 9). Temperature stability was maintained during sampling (Figure 10). Bulk density decreased, a probable result of higher moisture levels at the end of the experiment.

In spite of a greater than 10-fold increase in the TNT amendment compared with Experiment I, which resulted in 31.82- $\mu \mathrm{g} \mathrm{TNT} / \mathrm{g}$ and $1 \times 10^{6} \mathrm{DPM} / \mathrm{g}$ ODW of compost, no TNT was detected by HPLC-UV. The TNT detection limit by HPLC in the compost was $0.25-\mu \mathrm{g}$ TNT/g ODW. Therefore, test concentrations were well above detection limits. No radiolabeled $\mathrm{CO}_{2}$ or VOCs were detected. Complete combustion analysis of unextracted compost resulted in 64 and 57 percent recoveries of radiolabel from the compost containing TNT-amended clay and silt, respectively (Table 5). Therefore, total percent recoveries were 64 and 57 percent for composted clay and silt, respectively. The error term was 36 and 43 percent, respectively, an improvement over Experiment I errors.

More than half of the radiolabel was accounted for in the compost matrix (extractable plus unextractable compartments). Since no radiolabel was found in extracts of the compost, all of the radioactivity found in the combusted samples are attributable to the unextractable compartment. Therefore, all of the radiolabel was attributable to unextractable transformation products of TNT.

Microorganisms increased dramatically in response to incubation for $24 \mathrm{hr}$ in the compost matrix (Figure 8). After the first day, CFUs/g fell gradually over the rest of the 20-day compost period. Nevertheless, at 20 days, CFUs/g remained higher than initial levels. Therefore, the compost maintained significant bioactivity throughout the compost period.

\section{Experiment III}

Once most of the operational problems were solved, an experiment to better determine the mass balance of TNT in the small-scale reactors was initiated. Mean operational parameters are presented in Table 6. Carbon dioxide evolution (Figure 11) and temperature (Figure 12) were stable. Bulk density increased in both clay and silt reactors. Microbial populations according to 


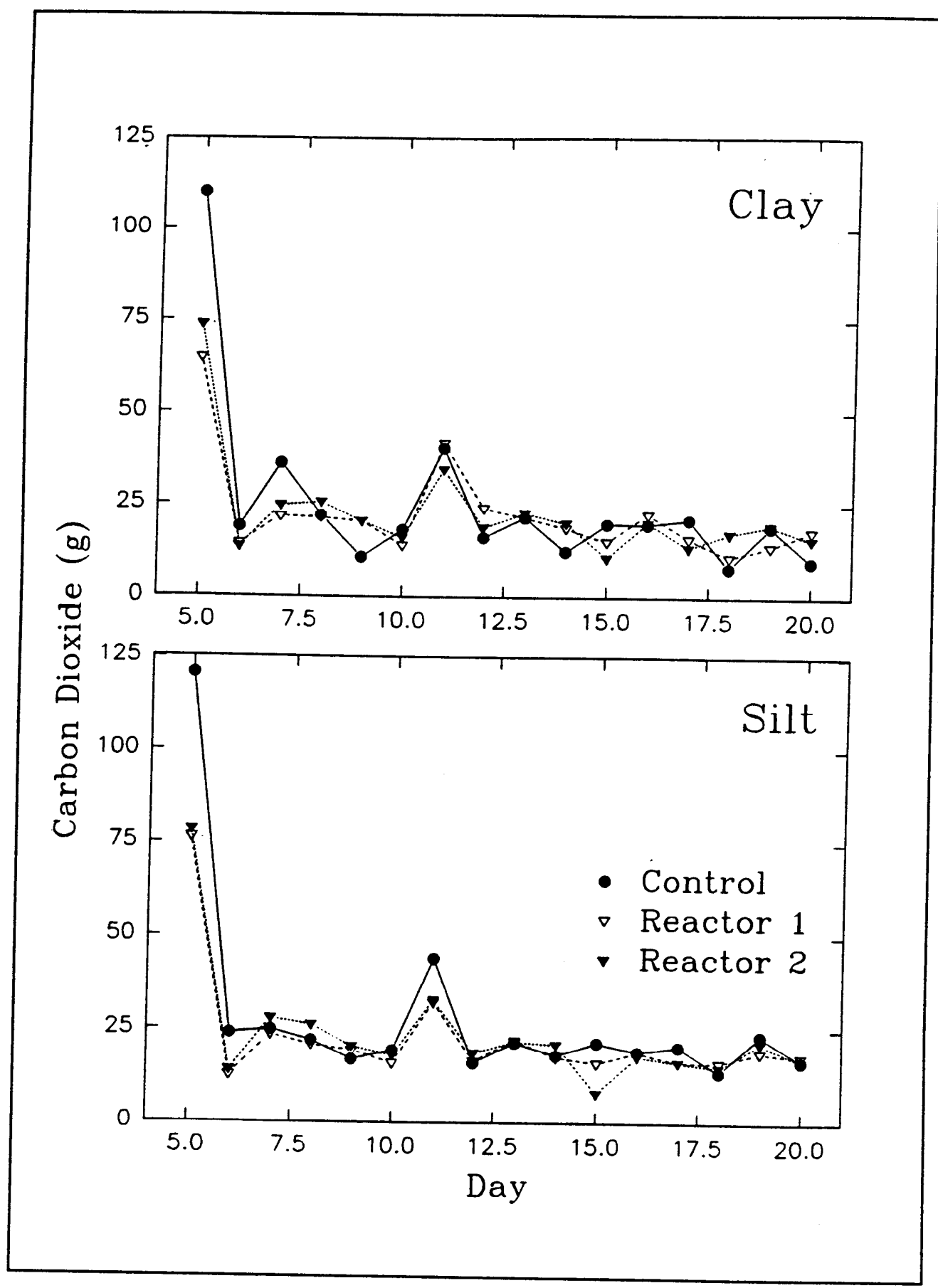

Figure 9. Daily total carbon dioxide evolved from each reactor from Experiment II 


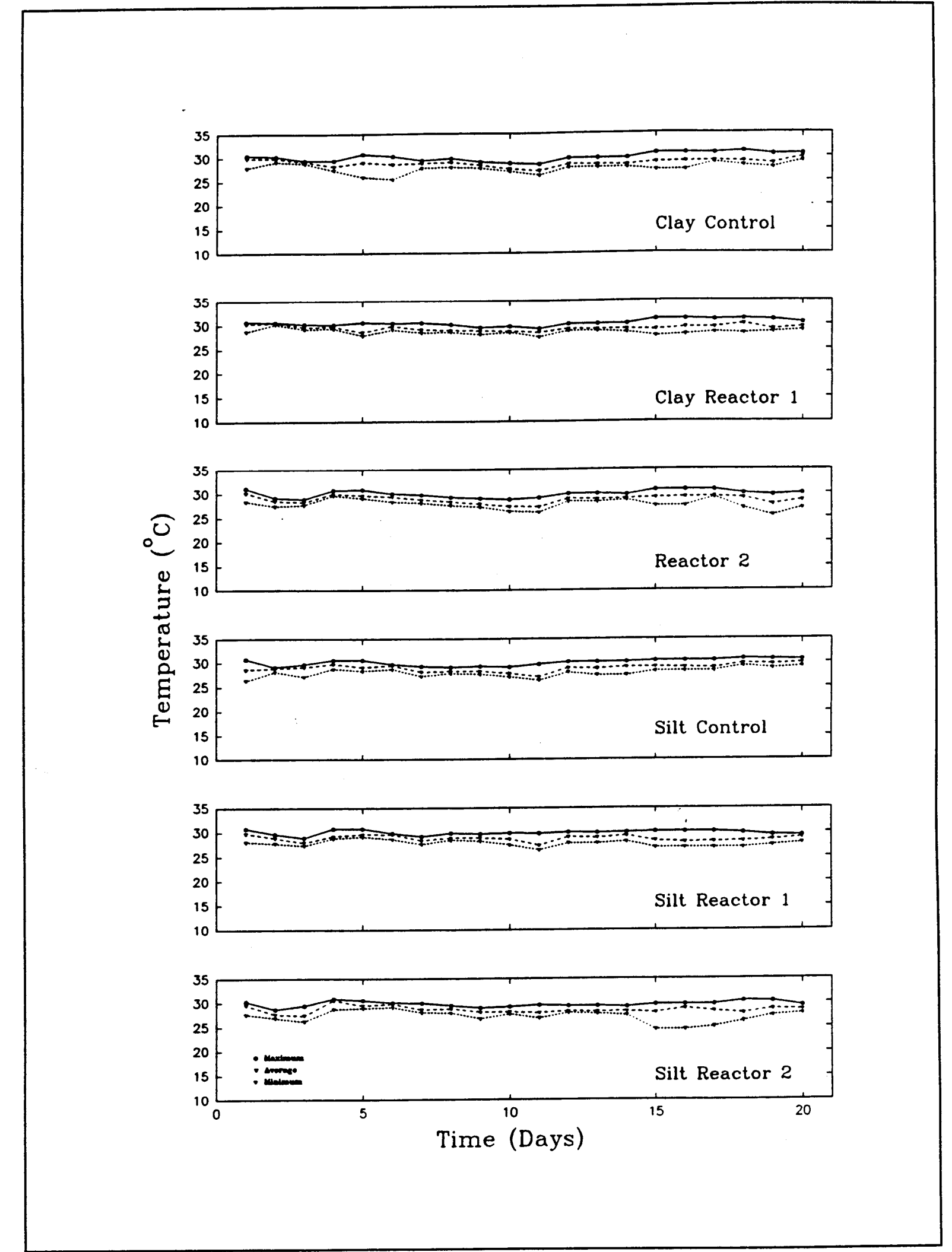

Figure 10. Mean daily maximum, average, and minimum temperatures in composted clay and silt reactors from Experiment II. Each datum point represents average of 30-min readings recorded in each $24-\mathrm{hr}$ period. Controls received no TNT 


\begin{tabular}{|c|c|c|c|c|c|}
\hline \multicolumn{6}{|c|}{$\begin{array}{l}\text { Table } 5 \\
\text { Percent Recoveries of Radiolabel from All Compartments in } \\
\text { Experiment II }\end{array}$} \\
\hline \multirow[b]{2}{*}{ Treatment } & \multicolumn{2}{|c|}{ Compost } & \multirow[b]{2}{*}{ Vocs } & \multirow[b]{2}{*}{$\mathrm{CO}_{2}$} & \multirow[b]{2}{*}{ Total } \\
\hline & Combustion & HPLC/Radio & & & \\
\hline Clay control & $N^{2}$ & ND & ND & ND & ND \\
\hline Clay TNT 1 & 65.42 & ND & ND & 0.70 & 66.12 \\
\hline Clay TNT 2 & 62.85 & ND & ND & 0.60 & 63.45 \\
\hline Silt control & ND & ND & ND & ND & ND \\
\hline Silt TNT 1 & 58.15 & ND & ND & 0.61 & 58.76 \\
\hline Silt TNT 2 & 55.30 & ND & ND & 0.50 & 55.80 \\
\hline
\end{tabular}

\begin{tabular}{|c|c|c|}
\hline \multicolumn{3}{|c|}{$\begin{array}{l}\text { Table } 6 \\
\text { Mean Operational Parameters for Experiment III ( } \pm \text { standard } \\
\text { error) }\end{array}$} \\
\hline Parameter & Clay & Silt \\
\hline Total $\mathrm{CO}_{2}, \mathrm{mg} /$ day & $2,842 \pm 865$ & $2,843 \pm 743$ \\
\hline Temperature, ${ }^{\circ} \mathrm{C}$ & $32 \pm 0.43$ & $31 \pm 0.37$ \\
\hline Bulk density increase, $\%$ & $20 \pm 2.7$ & $26 \pm 2.5$ \\
\hline Microorganisms at $T_{20}, \mathrm{CFUs} / \mathrm{g}$ & $1.26 \times 10^{9}$ & $2.29 \times 10^{9}$ \\
\hline
\end{tabular}

direct counts remained slightly higher at the end of this experiment than was the case in the first two experiments. Maximum populations after composting were in the $10^{9}$ CFUs/g range.

Summation of radioactivity recovered from the compost and $\mathrm{CO}_{2}$ resulted in $95.8 \pm 4.1$ and $71.4 \pm 9.8$ percent recoveries for composted clay and silt, respectively (Table 7). Only $0.4 \pm 0.03$ and $0.53 \pm 0.00$ percent of this was ${ }^{14} \mathrm{CO}_{2}$ from the clay and silt, respectively. No radioactivity was observed in VOC traps. Even with 350- $\mu$ TNT/g soil added to tests, analysis of extractable compost by HPLC resulted in no detection of TNT or transformation products by UV. These results indicate that TNT was converted into some unextractable form that remained in the compost matrix. 


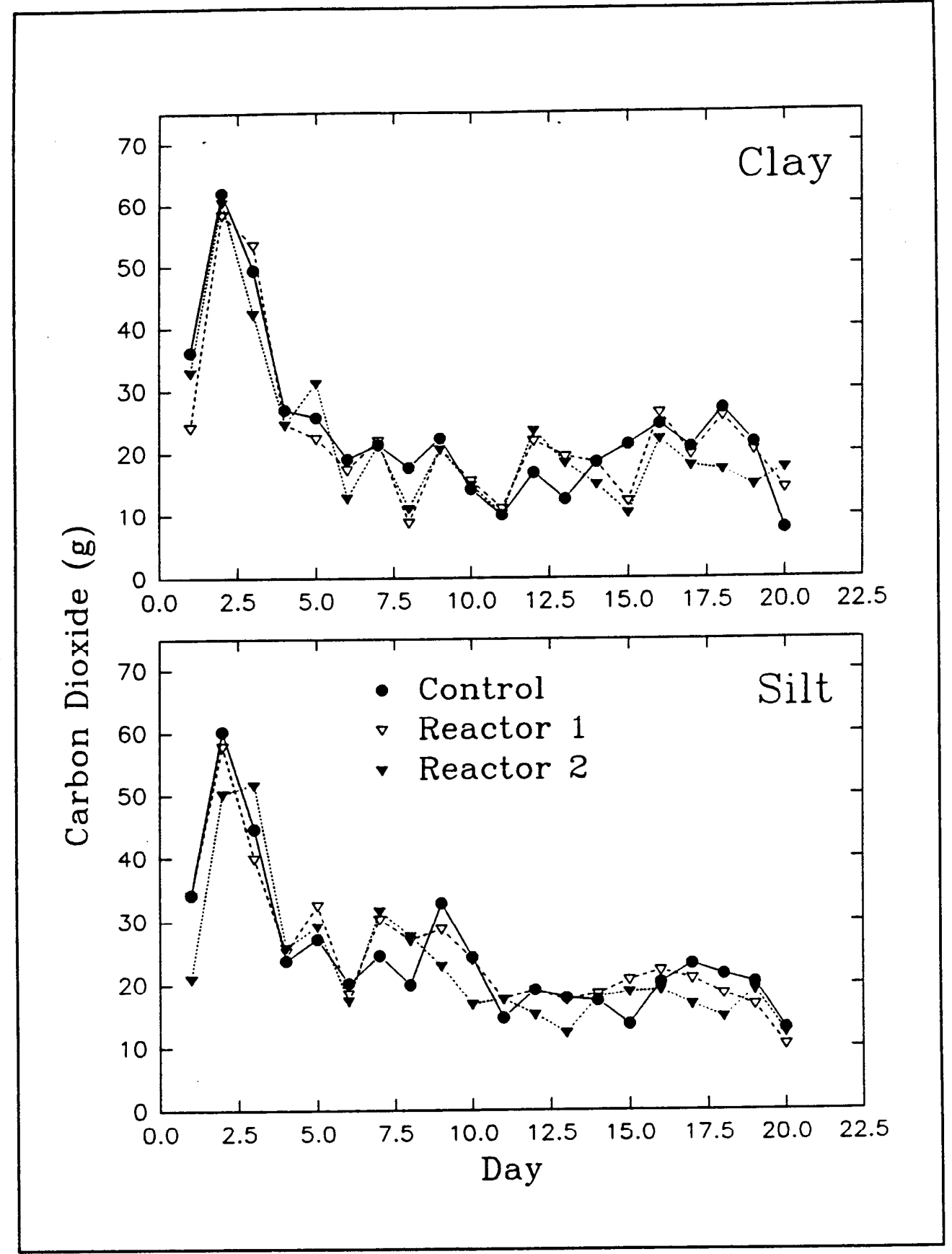

Figure 11. Daily total carbon dioxide evolved from each reactor from Experiment III

\section{Experiment IV}

\section{Thermophillc composting}

Maintaining a high temperature with an open water bath presented some difficulties. Evaporation rates were high at $55^{\circ} \mathrm{C}$, necessitating continuous replenishment of the water bath, with concomitant fluctuations in compost 

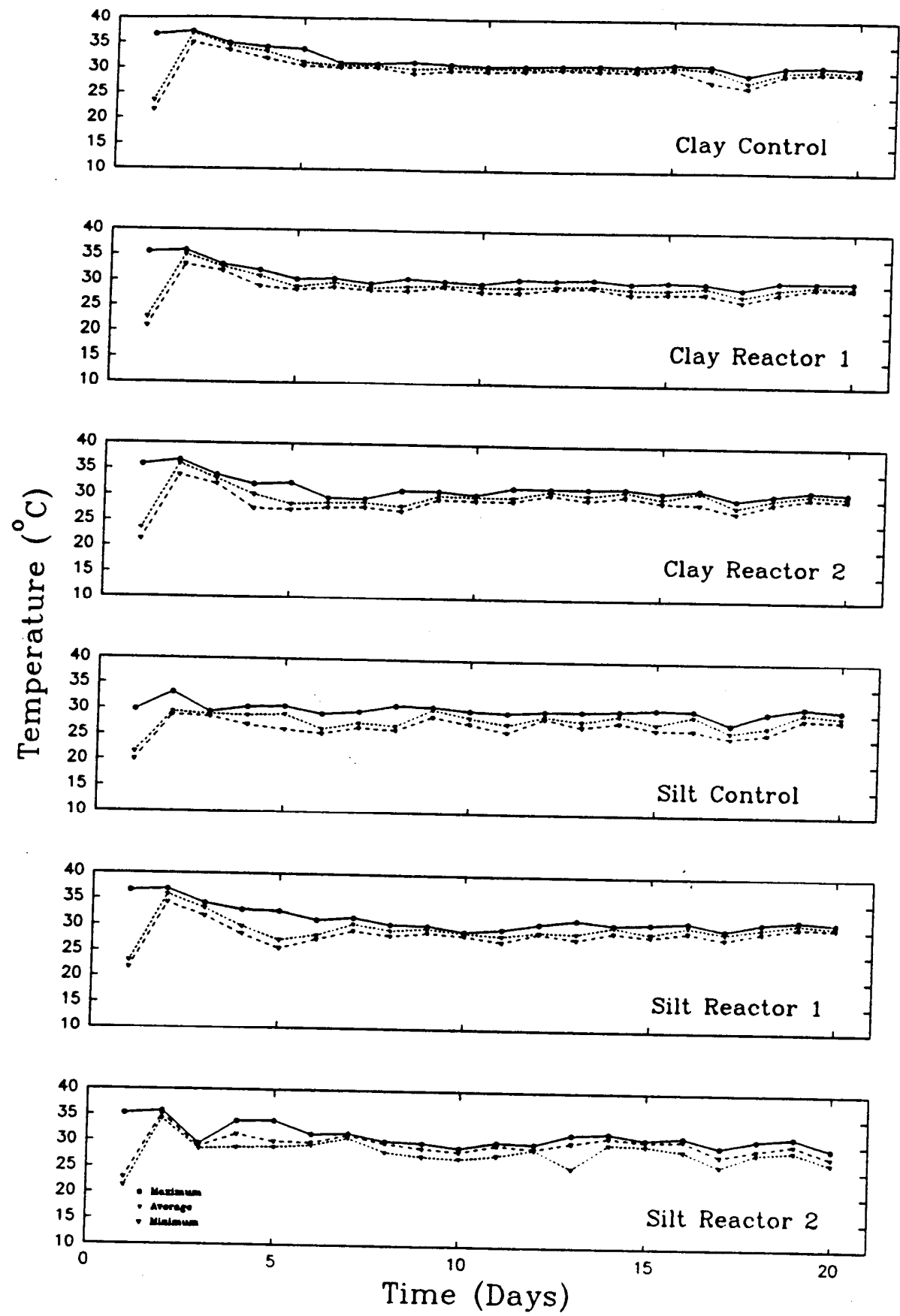

Figure 12. Mean daily maximum, average, and minimum temperatures in composted clay and silt reactors from Experiment III. Each datum point represents average of 30-min readings recorded in each $24-\mathrm{hr}$ period. Controls received no TNT 


\begin{tabular}{|c|c|c|c|c|c|}
\hline \multicolumn{6}{|c|}{$\begin{array}{l}\text { Table } 7 \\
\text { Percent Recoveries of Radiolabel from All Compartments in } \\
\text { Experiment III }\end{array}$} \\
\hline \multirow[b]{2}{*}{ Troatment } & \multicolumn{2}{|c|}{ Compost } & \multirow[b]{2}{*}{ Vocs } & \multirow[b]{2}{*}{$\mathrm{CO}_{2}$} & \multirow[b]{2}{*}{ Total $^{1}$} \\
\hline & Combustion & HPLC/UV & & & \\
\hline Clay control & $\mathrm{ND}^{2}$ & ND & ND & ND & ND \\
\hline Clay TNT 1 & 91.78 & ND & ND & 0.40 & 92.18 \\
\hline Clay TNT 2 & 99.90 & ND & ND & 0.47 & 100.37 \\
\hline Silt control & ND & ND & ND & ND & ND \\
\hline Silt TNT 1 & 81.19 & ND & ND & 0.53 & 81.72 \\
\hline Silt TNT 2 & 61.59 & ND & ND & 0.53 & 61.12 \\
\hline
\end{tabular}

temperature as the water level in the bath dropped below the compost material level ovemight. Fittings and seals were also more difficult to maintain. The temperature range was wider than for other mesophilic experiments, and the average temperature $\left(46 \pm 6.6^{\circ} \mathrm{C}\right.$, Figure 13) was at the low end of the thermophilic range of 45 to $65^{\circ} \mathrm{C}$ (Alexander 1977).

Mean total $\mathrm{CO}_{2}$ production was $23.00 \pm 1.8 \mathrm{mg}$ per day (Figure 14), which is typical of the $\mathrm{CO}_{2}$ produced in other experiments, both mesophilic and thermophilic.

Populations of mesophilic microorganisms, which may have been present as viable spores and other resting stages in the thermophilic environment, peaked at 10 days in the composted silt with $(5.3 \pm 1.2) \times 10^{9}$ colony-forming units (CFUs) per $g$ (ODW) (Figure 15). Mesophiles in the composted clay were relatively constant throughout the experimental period, averaging $(3.0 \pm 0.7) \times$ $10^{8} \mathrm{CFUs} / \mathrm{g}$ (Figure 15). Thermophilic microorganisms peaked at 15 days, with $(3.3 \pm 1.3) \times 10^{9}$ and $(5.2 \pm 1.5) \times 10^{8}$ CFUs per gram in silt and clay, respectively (Figure 15).

Bulk densities of treatments before and after composting did not differ significantly (Table 8).

\section{Mass balance}

Complete combustion of composted material. Complete combustion analysis of composted material resulted in recovery of essentially all the added radioactivity (Table 9). Means of all TNT treatments except one were within 


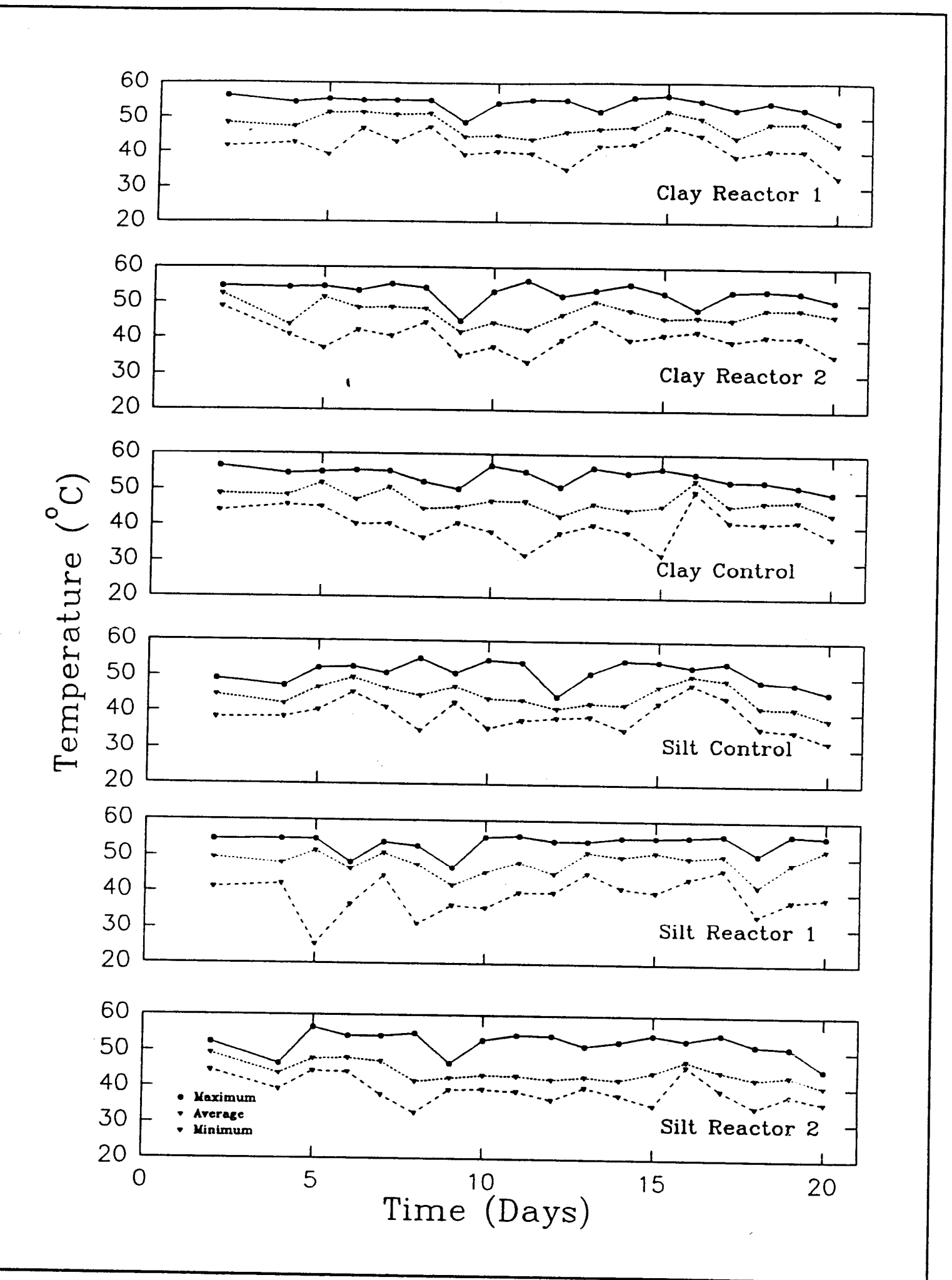

Figure 13. Mean daily maximum, average, and minimum temperatures in composted clay and silt reactors from Experiment IV. Each datum point represents average of all 30 min readings recorded in each 24-hr period. Controls received no TNT 


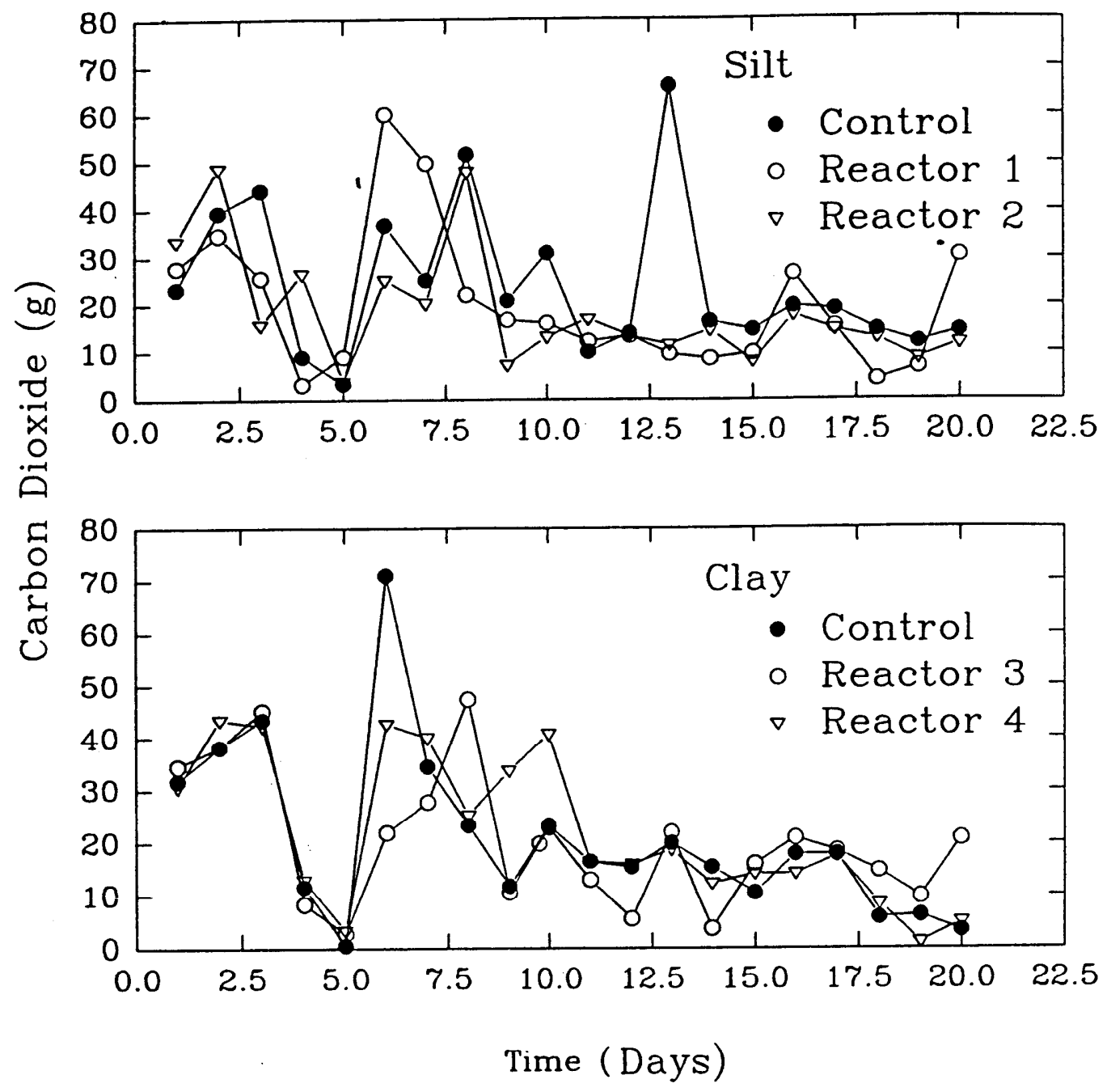

Figure 14. Daily total carbon dioxide evolved from each reactor from Experiment IV. Each datum point represents sum of two traps in series

one standard deviation unit of 100 percent. This result indicates that virtually all of the added radioactivity remained in the compost matrix after 20 days.

Fractionation of composted material. Fractionation resulted in poor total recoveries; however, significantly more of the radioactivity (30 percent) was recovered from the insoluble fraction (cellulose + humin) than from other 


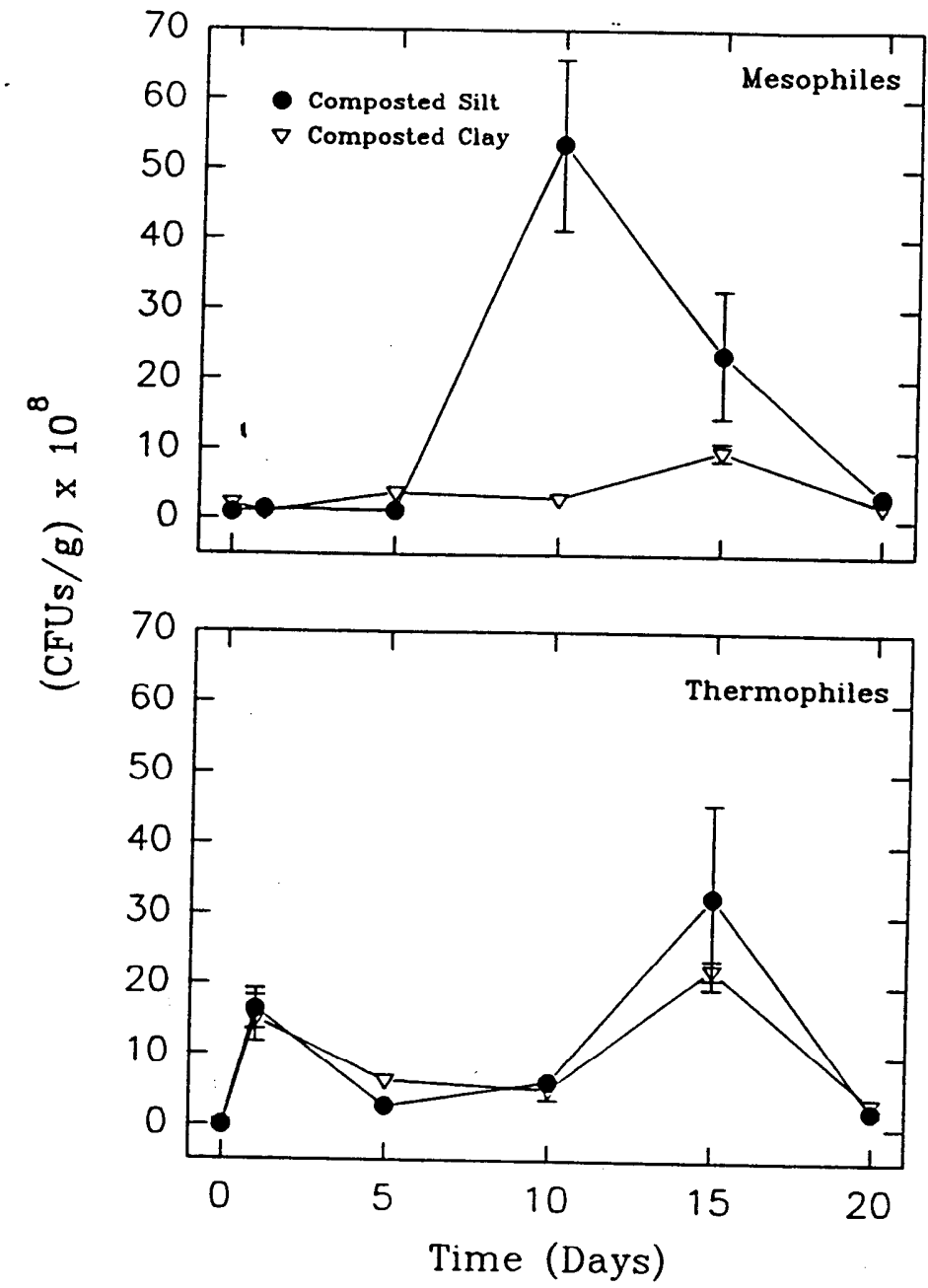

Figure 15. Microbial populations as determined by direct plate counts of composted silt and clay from Experiment IV. Each datum point represents mean of three plate counts of a dilution exhibiting 30 to 300 CFUs per $\mathrm{g}$ of compost (ODW). Upper graph represents populations of mesophiles (incubated at $30^{\circ} \mathrm{C}$ ), and lower graph represents populations of thermophiles (incubated at $60^{\circ} \mathrm{C}$ ). Vertical bars are standard errors

fractions (Table 10). Only 7.4 percent of the radioactivity was solvent extractable (ether, acetone, and acetonitrile extracts combined).

Recoveries of radiolabeled $\mathrm{CO}_{2}$ and VOCs. Only $0.45 \pm 0.15$ percent of added radioactivity was recovered as $\mathrm{CO}_{2}$ from silt and clay reactors. No radioactive VOCs were detected. 


\begin{tabular}{|c|c|c|c|}
\hline \multicolumn{4}{|c|}{$\begin{array}{l}\text { Table } 8 \\
\text { Bulk Densities }\left(\mathrm{g} / \mathrm{cm}^{3}\right) \text { Before and After Composting }\end{array}$} \\
\hline Experiment & Treatment & $T_{0}$ & $T_{20}$ \\
\hline 1 & $\begin{array}{l}\text { Clay Control } \\
\text { Silt Control } \\
\text { Clay Treatments }{ }^{2} \\
\text { Silt Treatments }\end{array}$ & $\begin{array}{l}0.182 \\
0.16 \\
0.154 \pm 0.0075 \\
0.158 \pm 0.0040\end{array}$ & $\begin{array}{l}0.131 \\
0.099 \\
0.142 \pm 0.0095 \\
0.127 \pm 0.0070\end{array}$ \\
\hline II & $\begin{array}{l}\text { Unautoclaved } \\
1 / 3 \text { Unautoclaved } \\
\text { Autodaved }\end{array}$ & $\begin{array}{l}0.178 \pm 0.010 \\
0.172 \pm 0.037 \\
0.200 \pm 0.076\end{array}$ & $\begin{array}{l}0.144 \pm 0.0025 \\
0.142 \pm 0.0050 \\
0.132 \pm 0.0075\end{array}$ \\
\hline III & $\begin{array}{l}\text { Control }^{3} \\
\text { Umatilla }\end{array}$ & $\begin{array}{l}0.188 \pm 0.00 \\
0.152 \pm 0.0079\end{array}$ & $\begin{array}{l}0.135 \pm 0.013 \\
0.166 \pm 0.020\end{array}$ \\
\hline \multicolumn{4}{|c|}{$\begin{array}{l}1 \text { Only one reactor for each soil type was a control receiving no radiolabeled TNT. } \\
2 \text { Each soil was composted in two replicates for Experiment I; each treatment was composted } \\
\text { in two replicates for Experiment II. } \\
3 \text { The two control replicates of Umatilla soil received no radiolabeled TNT. } \\
4 \text { Four replicates of Umatilla soil received radiolabeled TNT. }\end{array}$} \\
\hline
\end{tabular}

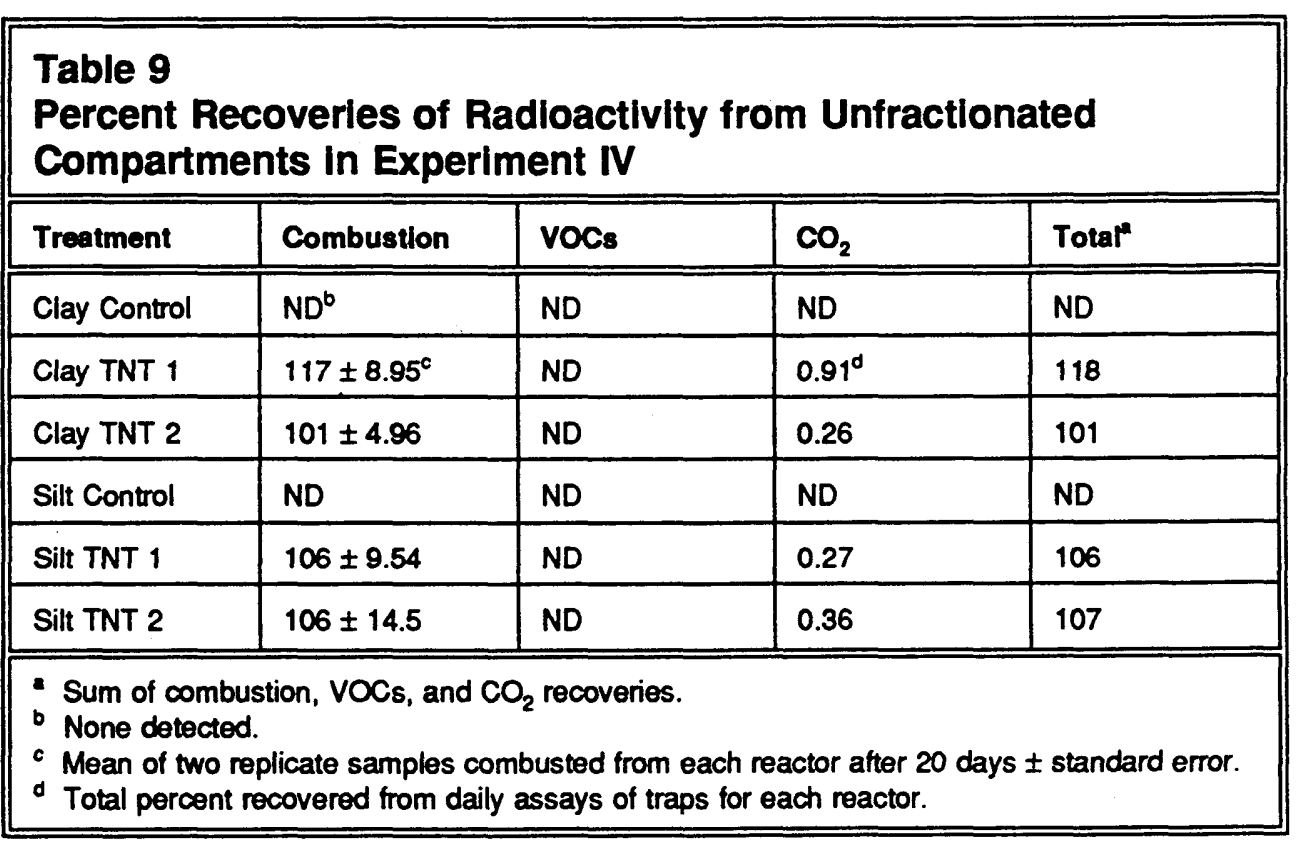

\section{Experiment $\mathbf{V}$}

Autoclaving of compost exerted no effect upon the mesophilic temperature regime (Figure 16) nor upon the total $\mathrm{CO}_{2}$ generated (Figure 17). Overall mean temperatures for unautoclaved $\left(27.21 \pm 0.16^{\circ} \mathrm{C}\right)$, one-third unautoclaved $\left(27.15 \pm 0.32^{\circ} \mathrm{C}\right)$, and autoclaved $\left(27.08 \pm 0.041^{\circ} \mathrm{C}\right)$ treatments did not differ significantly. Total mean $\mathrm{CO}_{2}$ production for unautoclaved $(20.44 \pm 1.93 \mathrm{~g})$, one-third unautoclaved $(18.49 \pm 2.33 \mathrm{~g})$, and autoclaved $(17.68 \pm 1.45 \mathrm{~g})$ treatments did not differ significantly. Both temperature and total $\mathrm{CO}_{2}$ were typical of previous mesophilic experiments. 


\begin{tabular}{|l|l|}
\hline $\begin{array}{l}\text { Table 10 } \\
\text { Percent Recoveries of Radioactivity from Compost Fractions in } \\
\text { Experiment IV }\end{array}$ \\
\hline \hline Fraction & Percent Rocovery \\
\hline \hline Ether Extract & 5.5 \\
\hline Acetone Extract & 1.8 \\
\hline Acetonitrile Extract & 0.1 \\
\hline Cellulose + Humin & 30.0 \\
\hline Humic Acid & 11.0 \\
\hline Fulvic Acid & 3.1 \\
\hline
\end{tabular}

Autoclaving all of the compost and two-thirds of the compost reduced the microbial counts at the initial sampling time only (Figure 18). Either autoclaving was insufficient to completely eliminate all the microflora, including spores, or sterile conditions were not maintained over time. Autoclaving may have released nutrients from the compost, which promoted the recovering microbial populations to numbers slightly above those of the unautoclaved tests at 10 and 20 days. Because microbial populations recovered so rapidly, no conclusion concerning abiotic transformations of TNT in the compost can be drawn.

Bulk densities of treatments before and after composting did not differ significantly (Table 8). Bulk densities decreased slightly from $T_{0}$ to $T_{20}$, perhaps because of swelling of particles as they adsorbed more water during the course of the composting.

\section{Mass balance}

Complete combustion of composted material. Recoveries of radioactivity were unusually high (Table 11). These results are due to problems with the sample oxidizer, which were subsequently corrected. Unfortunately, insufficient sample remained to recombust the composted material.

Fractionation of composted material. Recovery of radioactivity from the combination of the two extracting solvents, ether and acetonitrile, was comparable to total recoveries when all three solvents were used (Experiment IV). Therefore, omitting acetone from the fractionation scheme had no adverse effect upon recoveries. As anticipated, omission of acetone reduced the stripping of humics into the solvent fractions. Fractionation of the alkaline insoluble fraction (cellulose + humin) with MIBK resulted in three phases-an MIBK phase containing the humin, an insoluble phase (cellulose), and an aqueous phase. The aqueous phase consisted of slightly alkaline water forced 

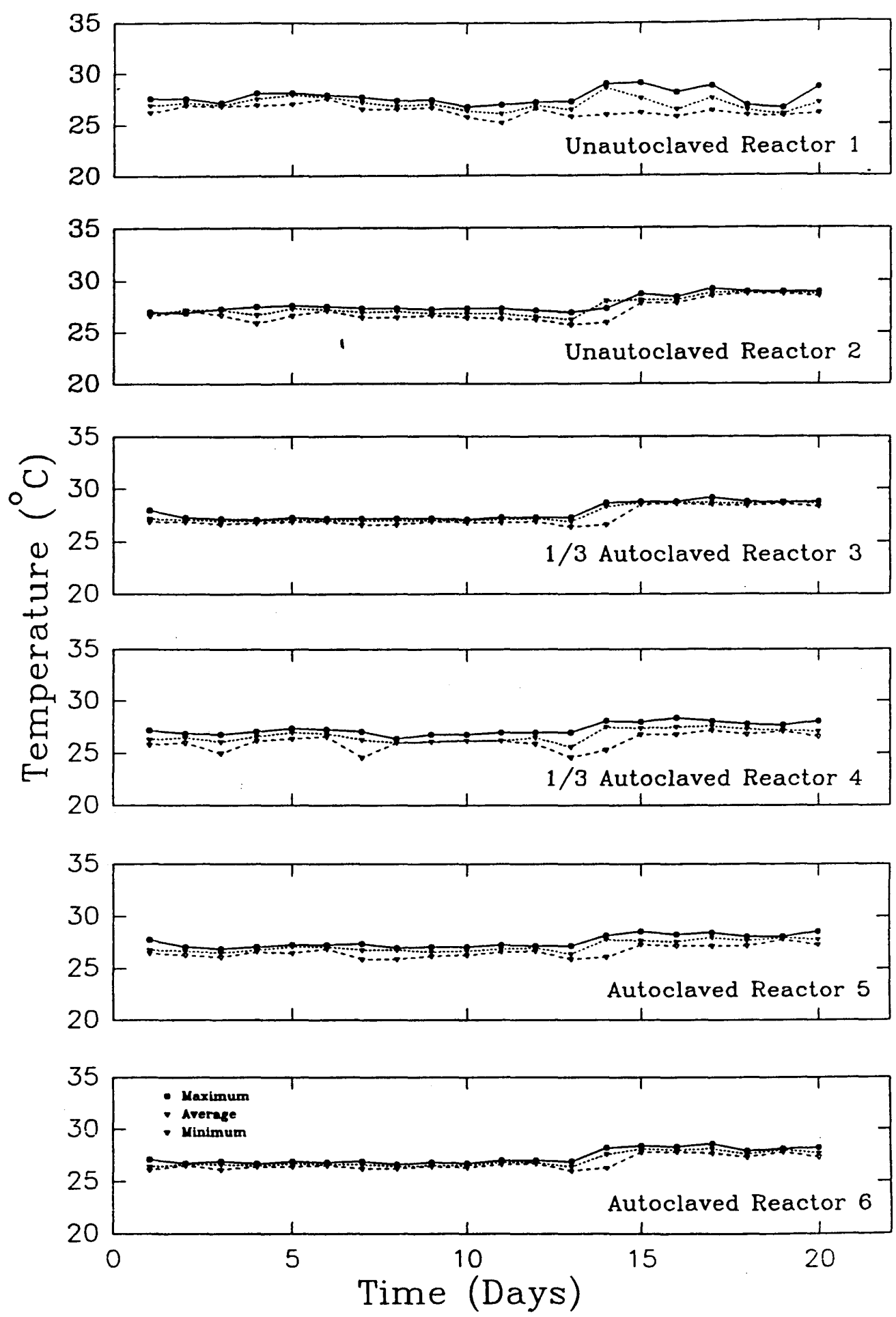

Figure 16. Mean daily maximum, average, and minimum temperatures in composted Umatilla soil from Experiment $V$. Each datum point represents average of 30-min readings recorded in each 24 -hr period 

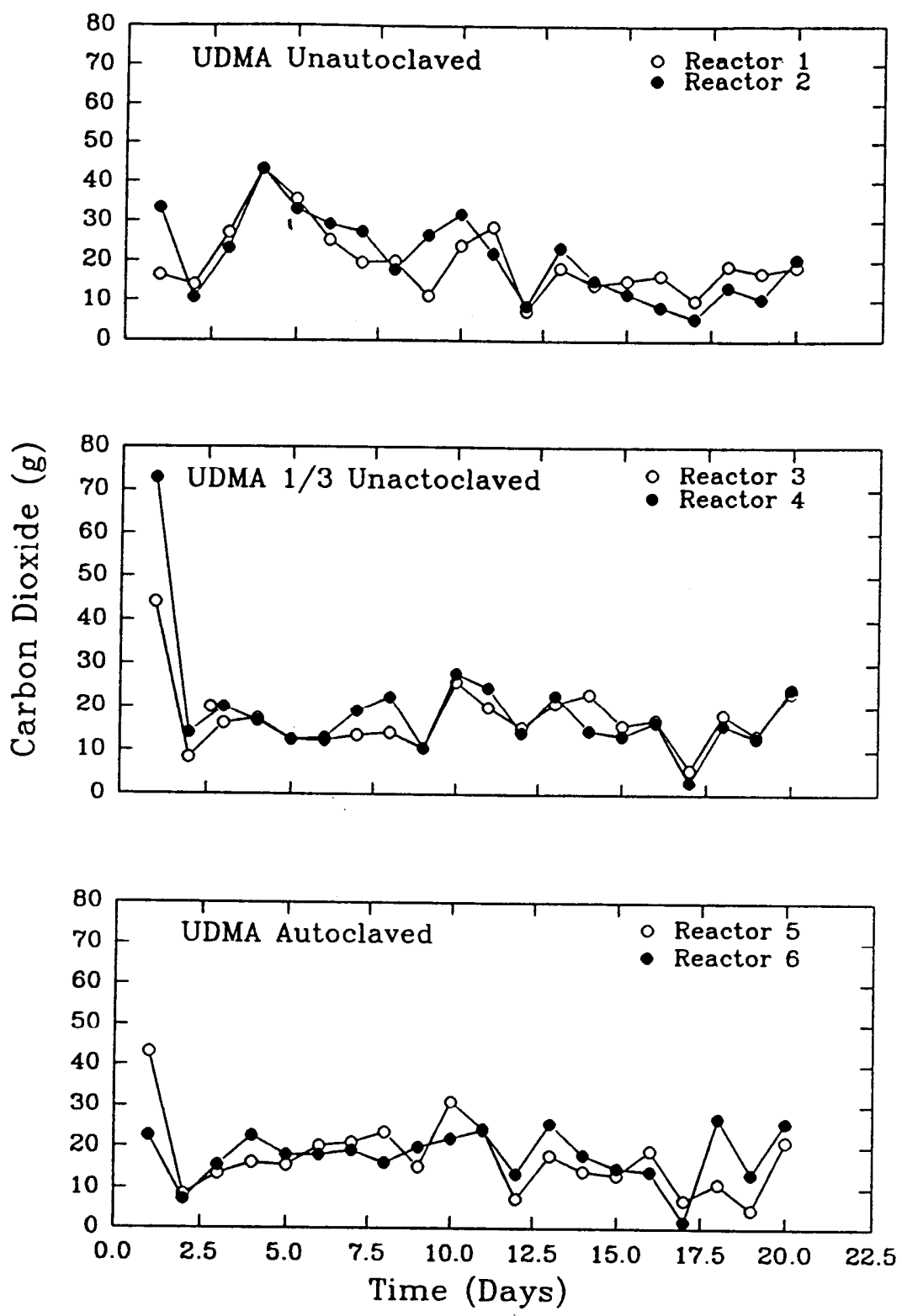

Figure 17. Daily total carbon dioxide evolved from each reactor from Experiment $V$ 


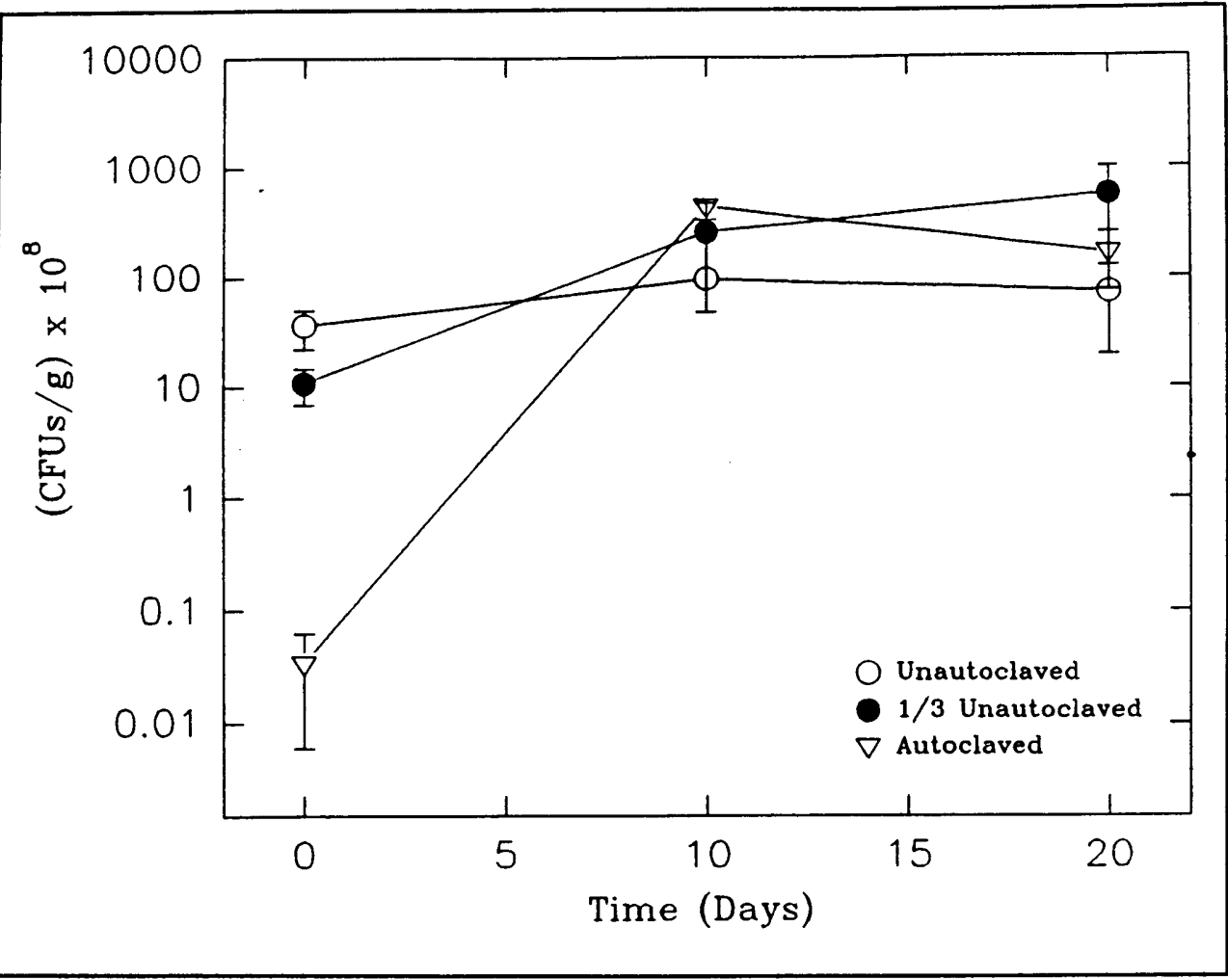

Figure 18. Microbial populations as determined by direct plate counts of composted Umatilla soil from Experiment V. Each datum point represents mean of three plate counts of a dilution exhibiting 30 to 300 CFUs per $g$ of compost (ODW). Vertical bars are standard errors of mean

\begin{tabular}{|c|c|c|c|c|}
\hline \multicolumn{5}{|c|}{$\begin{array}{l}\text { Table } 11 \\
\text { Percent Recoveries of Radioactivity from Unfractionated Com- } \\
\text { partments In Experiment V }\end{array}$} \\
\hline Treatment & Combustion & Vocs & $\mathrm{CO}_{2}$ & Totap" \\
\hline Unautoclaved 1 & $144 \pm 5.07^{\circ}$ & $N D^{C}$ & $0.67^{\circ}$ & 144 \\
\hline Unautoclaved 2 & $103 \pm 5.53$ & ND & 0.60 & 104 \\
\hline 1/3 Unautoclaved 1 & $181 \pm 3.58$ & ND & 0.15 & 181 \\
\hline 1/3 Unautoclaved 2 & $186 \pm 4.67$ & ND & 0.26 & 186 \\
\hline Autoclaved 1 & $117 \pm 2.80$ & ND & 0.26 & 117 \\
\hline Autodaved 2 & $168 \pm 0.73$ & ND & 0.37 & 168 \\
\hline
\end{tabular}


from pore spaces in the humin/cellulose material by the MIBK. Therefore, the aqueous phase, which contained a suspension of insoluble material, was added to the basic humic/fulvic acid solution, where it underwent separation for humic acid and fulvic acid.

Results of radioassays of extraction residues were comparable with results for Experiment IV (Figure 19). Differences among treatments were minimal. The cellulose fraction accounted for most of the recovered radioactivity in all three treatments. The humin fraction was extremely small, approximately 0.5 percent in all treatments. Radioactivity in the separate fractions was approximately the same in all treatments, an indication that autoclaving exerted limited effect on the distribution of TNT and/or its transformation products. Total solvent extractable radioactivity was less than 20 percent $(17.76 \pm$ 1.37 percent). More than half of the radioactivity (57.61 \pm 4.50 percent) was accounted for in fractions that were unextractable with solvents.

Recoveries of radiolabeled $\mathrm{CO}_{2}$ and VOCs. Less than 1 percent of the radioactivity was recovered as ${ }^{14} \mathrm{CO}_{2}$ (Table 11 ). Unautoclaved treatments generated significantly more ${ }^{14} \mathrm{CO}_{2}$ than other treatments, but levels were consistently low and typical of results of other experiments. Also consistent with other experiments was the absence of radiolabeled VOCs.

Recoveries of explosives and transformation products from composted material. Results of HPLC/ultraviolet (UV) analysis of composted material at $\mathrm{T}_{0}$ and $\mathrm{T}_{20}$ indicated only slight differences between treatments (Figure 20). The $T_{0}$ values for the explosives TNT, RDX, and HMX did not differ with treatment. Therefore, autoclaving exerted no effect upon concentrations of explosives in the compost. The $\mathrm{T}_{0}$ sample for the unautoclaved treatment was lost. However, the $T_{0}$ value for Experiment VI, which had the same composition and was also unautoclaved, is no different from the $T_{0}$ values for the onethird unautoclaved and the autoclaved samples in Experiment V. Therefore, the assumption that the Experiment $\mathrm{V} \mathrm{T}_{0}$ value would be the same as for other treatments is reasonable. The $T_{20}$ values for TNT and RDX decreased significantly from $T_{0}$ values, an indication that these explosives had been transformed or degraded during the composting process. The TNT and RDX levels in the two autoclaved treatments were lower than in the unautoclaved treatments. This may be due to release of nutrients during autoclaving, which promoted microbial transformation, and/or to changes in the chemical composition of the compost during autoclaving, which increased any abiotic processes such as sorption and chemical transformation. The HMX values were less affected by autoclaving showing only a slight decrease in the treatment where all of the compost was autoclaved, but no change in the one-third unautoclaved treatment.

Two of the transformation products of TNT, 4ADNT and 2ADNT, were detected in the $T_{0}$ and $T_{20}$ samples (Figure 20). The $T_{0}$ concentrations of 4ADNT were significantly less in the autoclaved treatments than in the one-third unautoclaved treatment. Autoclaving may have decreased the concentration of $4 A D N T$ already present in the compost at $T_{0}$. Concentrations 

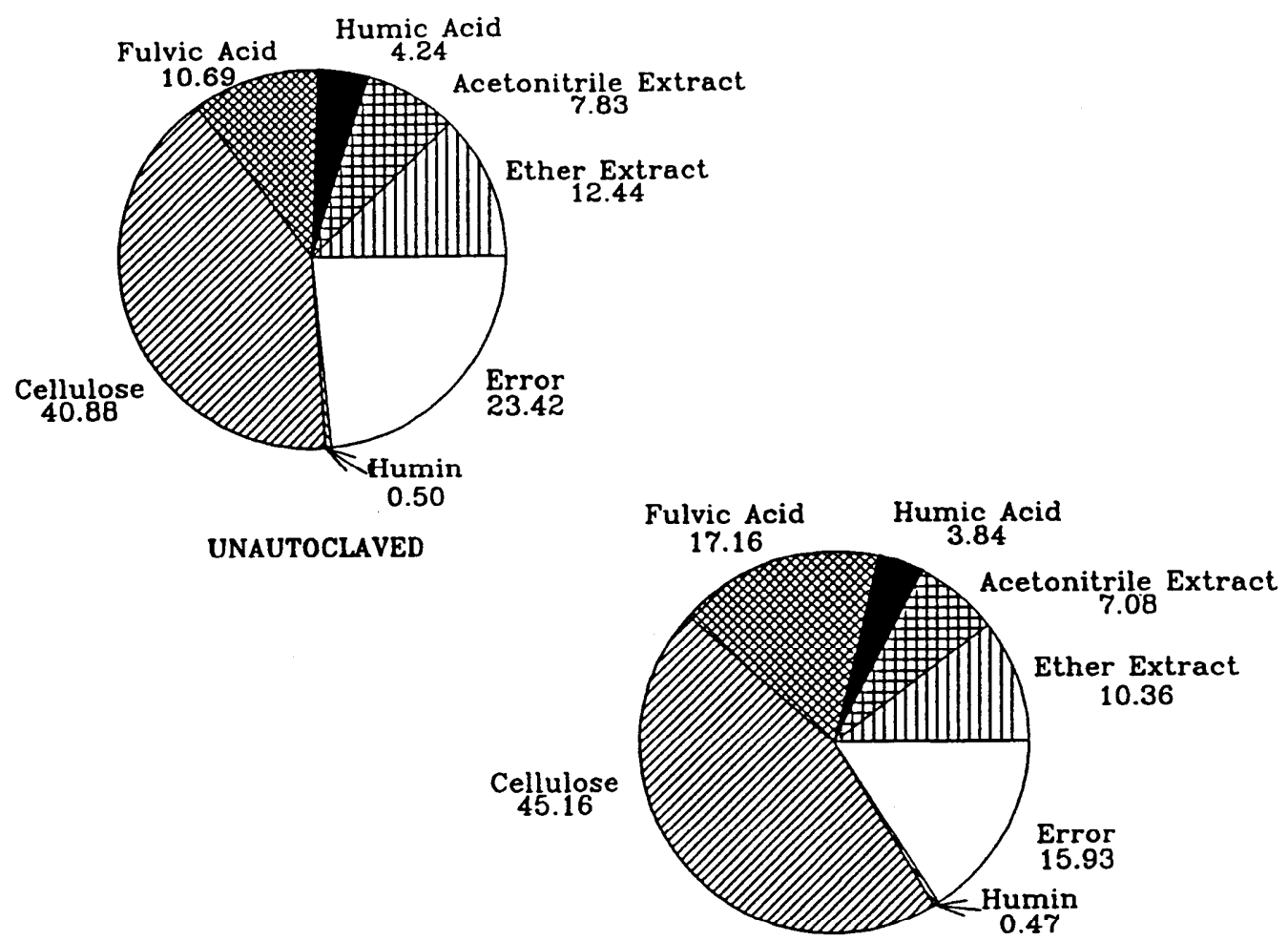

$1 / 3$ UNAUTOCLAVED

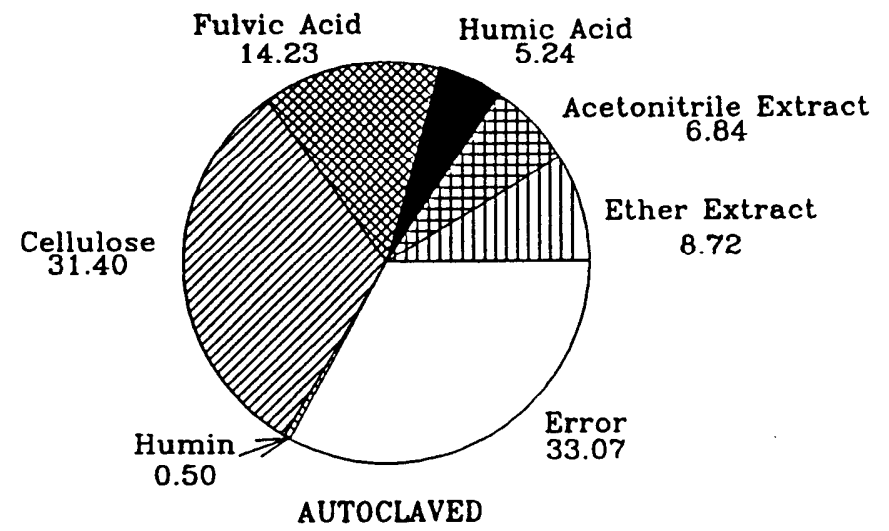

Figure 19. Percent recovery of added radioactivity in each fraction of composted Umatilla soil in Experiment V. Values are means of two replicate compost reactors 


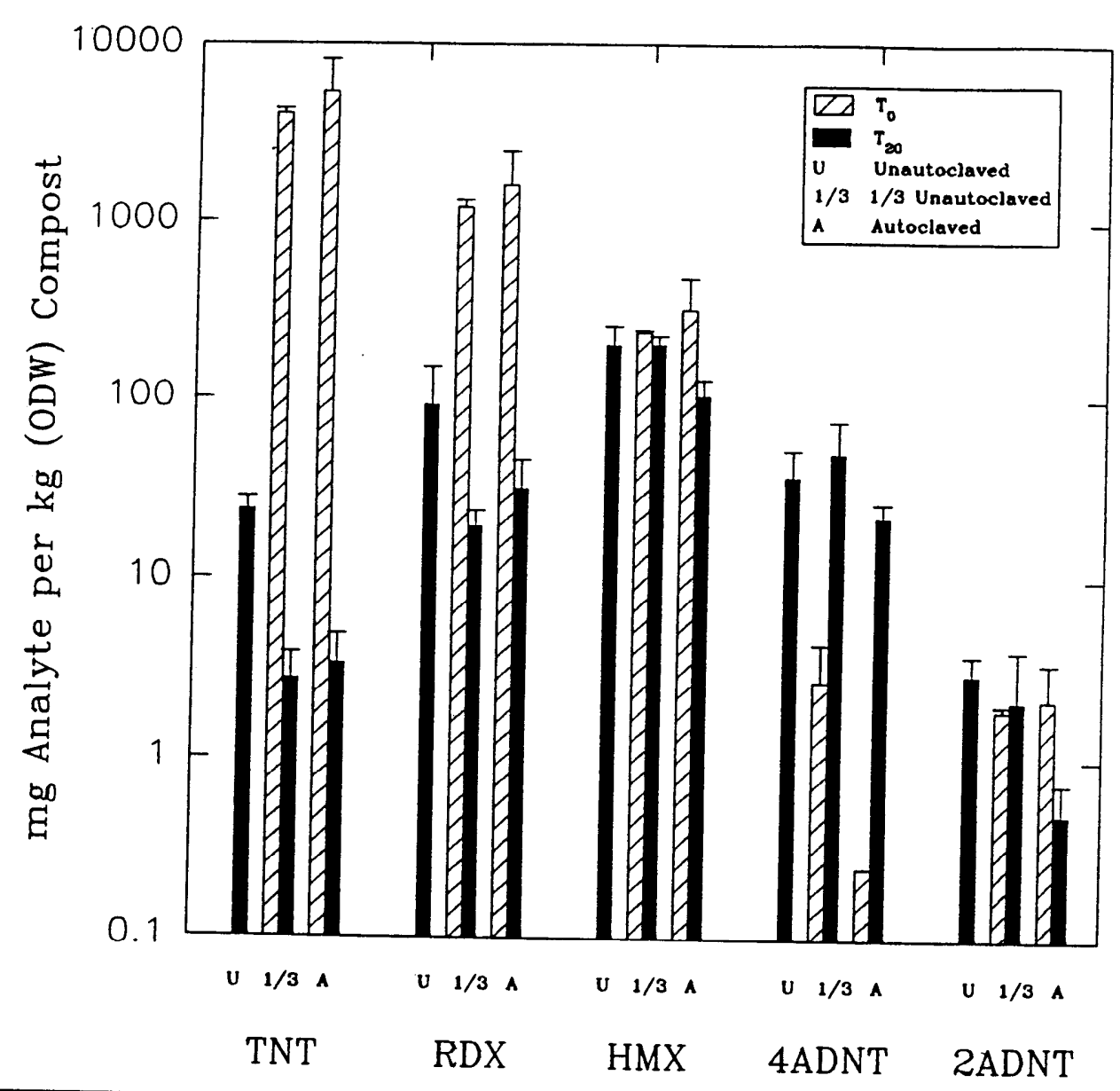

Figure 20. Results of HPLC/UV analysis of composted Umatilla soil from Experiment $V$ at $T_{0}$ and $T_{20}$. Means of two replicates are shown with standard error bars. The $T_{0}$ unautoclaved sample was lost

of 4ADNT increased dramatically in all treatments from $T_{0}$ to $T_{20}$, probably as a result of microbial transformation during the composting process. The $T_{20}$ concentrations of $4 \mathrm{ADNT}$ did not differ with treatment. Concentrations of 2ADNT at $\mathrm{T}_{0}$ did not differ with treatment, but the $\mathrm{T}_{20}$ autoclaved treatment was significantly less than other treatments (Figure 20). Concentrations of 2ADNT were significantly lower than concentrations of $4 A D N T$ at $T_{20}$. This result suggests that $4 A D N T$ formation is favored over 2ADNT formation during composting. This is not surprising since the para position on the TNT molecule is chemically more reactive than the meta position. Formation of 4ADNT and 2ADNT were insufficient to account for all of the decrease in TNT observed. Since no radiolabeled ${ }^{14} \mathrm{CO}_{2}$ nor VOCs were found, these results are consistent with radioassay results that indicated transformation of TNT to products that were unextractable for HPLC/UV analysis. 


\section{Experiment VI}

\section{Operational parameters}

Overall average temperature $\left(49.4 \pm 0.0410^{\circ} \mathrm{C}\right)$ was within the thermophilic range. Average temperature for the two control reactors $\left(51.5 \pm 0.045^{\circ} \mathrm{C}\right)$ was slightly higher than the average for the four reactors that had received radiolabeled TNT $\left(48.38 \pm 0.039^{\circ} \mathrm{C}\right)$. The small amount of radiolabeled TNT added to treated reactors relative to the high concentration of TNT already present from the soil (Table 2) should have had little effect on the temperature of the reactors. The differences observed are more likely a function of maintaining the reactors at high temperature, e.g., opening and closing reactors to seal leaks. The minimum temperature each day for each reactor (Figure 21) shows the fluctuations occasioned by such problems.

Total $\mathrm{CO}_{2}$ evolution from controls $(18.53 \pm 0.062 \mathrm{~g})$. was not significantly different from treatments $\left(17.88 \pm 0.87 \mathrm{~g}\right.$ ) (Figure 22). These $\mathrm{CO}_{2}$ values are slightly lower than values obtained in Experiment I with composted silt and clay soils $(23.00 \pm 1.8 \mathrm{~g})$, but are consistent with values obtained with composted UMDA soil in Experiment V (18.21 $\pm 0.26 \mathrm{~g})$.

Microbial populations followed the trend expected for thermophilic composting (Figure 23). The population of thermophilic microorganisms increased from $10^{6}$ CFUs per $g$ at $T_{0}$ to $10^{9}$ at $T_{20}$. The mesophilic population gradually declined from $10^{9}$ to $10^{8}$ because of the elevated temperature.

\section{Mass balance}

Complete combustion of composted material. The percent recovery of radioactivity from complete combustion of the four Umatilla treatments was $108.96 \pm 9.00$ percent (Table 12). This result indicates that essentially 100 percent of the added radioactivity remained in the compost matrix after 20 days.

Fractionation of composted material. Both ether, a nonpolar solvent, and acetonitrile, a polar solvent, were kept as the extraction solvents for TNT and transformation products to retain continuity with Experiments IV and V. In future experiments, switching to acetonitrile alone as the extraction solvent is recommended. Tests in the U.S. Army Engineer Waterways Experiment Station laboratory (data unreported) have shown that repeated extractions with acetonitrile removed most of the extractable explosives and their transformation products from both compost and soils. Use of acetonitrile alone would further reduce humic stripping without sacrificing recovery, and since acetonitrile is the extracting solvent of choice for HPLC analysis (EPA 1990), the comparability of fractionation data with data obtained from HPLC analysis would be improved. 


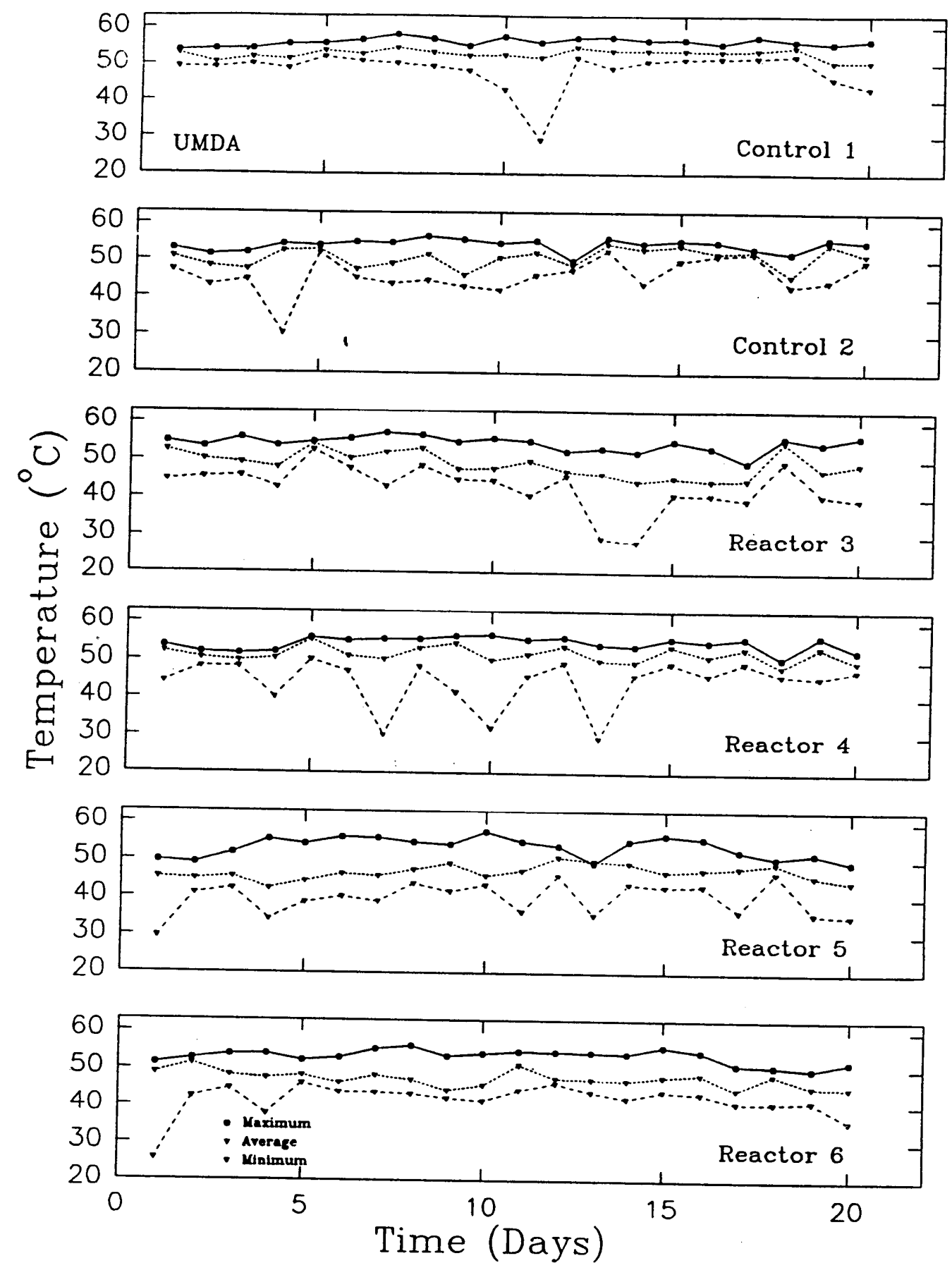

Figure 21. Mean daily maximum, average, and minimum temperatures in composted Umatilla reactors from Experiment VI. Each datum point represents average of 30-min readings recorded in each $24-\mathrm{hr}$ period. Controls received no radiolabeled TNT 


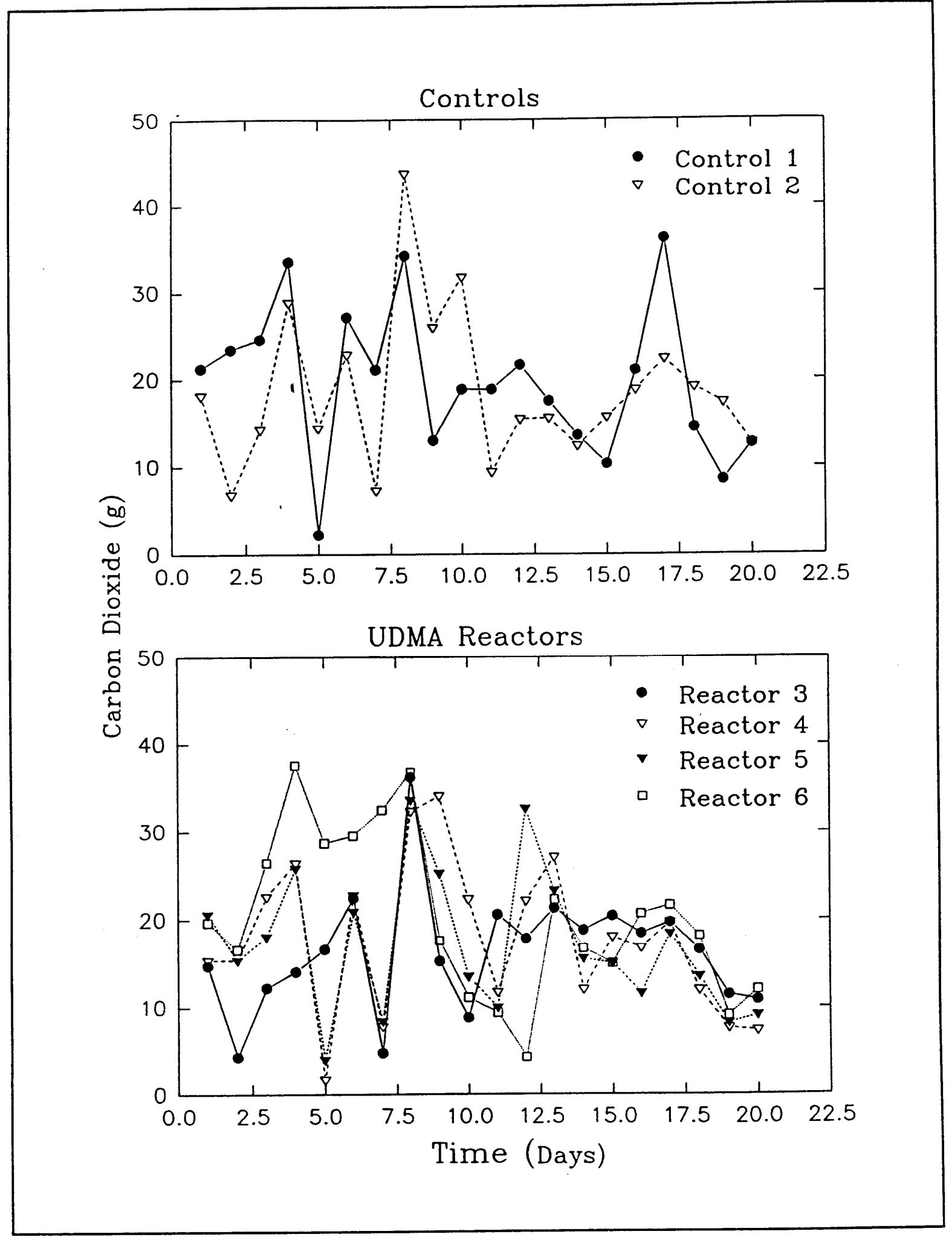

Figure 22. Daily total carbon dioxide evolved from each reactor from Experiment VI 


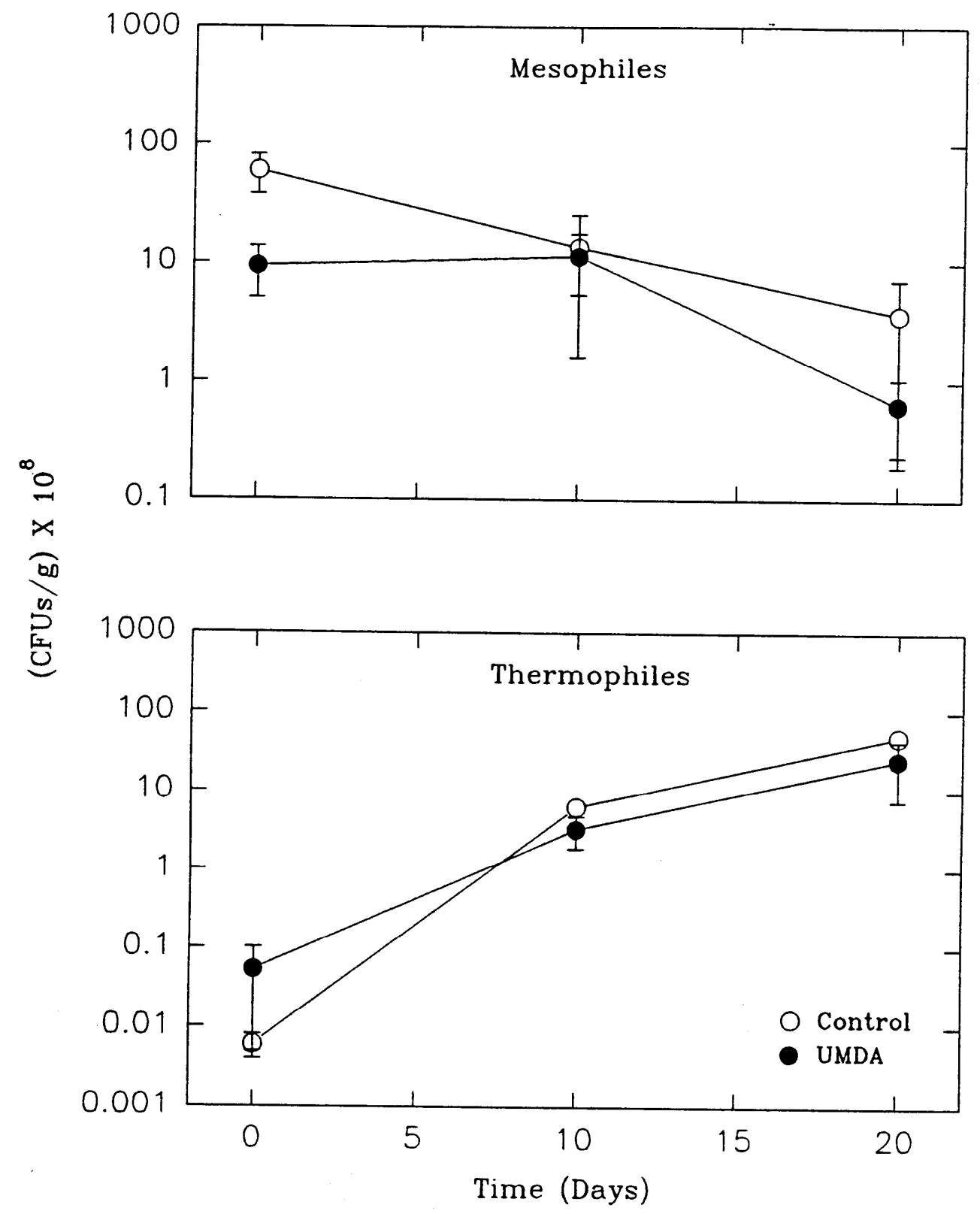

Figure 23. Microbial populations as determined by direct plate counts of composted Umatilla soil from Experiment VI. Each datum point represents mean of three plate counts of a dilution exhibiting 30 to 300 CFUs per $g$ of compost (ODW). Vertical bars are standard errors of mean 


\begin{tabular}{|c|c|c|c|c|}
\hline \multicolumn{5}{|c|}{$\begin{array}{l}\text { Table } 12 \\
\text { Percent Recoverles of Radioactivity from Unfractionated } \\
\text { Compartments In Experiment VI }\end{array}$} \\
\hline Treatment & Combustion & vocs & $\mathrm{CO}_{2}$ & Totap \\
\hline UMDA Control 1 & $\mathrm{ND}^{6}$ & ND & ND & ND \\
\hline UMDA Control 2 & ND & ND & ND & ND \\
\hline UMDA TNT 1 & $115 \pm 19.1^{c}$ & ND & $0.13^{d}$ & 115 \\
\hline UMDA TNT 2 & $128 \pm 3.07$ & ND & 0.13 & 128 \\
\hline UMDA TNT 3 & $85 \pm 15.4$ & ND & 0.20 & 85 \\
\hline UMDA TNT 4 & $107 \pm 5.15$ & ND & 0.22 & 107 \\
\hline \multicolumn{5}{|c|}{$\begin{array}{l}\text { Sum of combustion, } V O C s, \text { and } \mathrm{CO}_{2} \text { recoveries. } \\
\text { None detected. } \\
\text { Means of four replicate samples combusted from each reactor after } 20 \text { days } \pm \text { standard } \\
\text { error. }\end{array}$} \\
\hline
\end{tabular}

Although total percent recovery of the radioactivity ( 96.4 percent) was better than in previous experiments, the relative distribution among fractions was comparable (Figure 24). Most of the radioactivity (31.98 percent) was recovered in the cellulose fraction. Humin represented a larger portion (21.94 percent) than in the previous experiment, but this is due to refinements in the fractionation procedure. The amount of solvent extractable radioactivity and the humic and fulvic acid fractions were very similar to those of Experiment V.

Evolution of ${ }^{14} \mathrm{CO}_{2}$ and VOCs. Only $0.17 \pm 0.023$ percent of the radioactivity was recovered as ${ }^{14} \mathrm{CO}_{2}$. This value is comparable with $\mathrm{CO}_{2}$ recoveries from previous experiments, which were generally less than 1 percent. As for all other compost experiments, no VOCs were detected.

HPLC/UV analysis of composted material. Concentrations of TNT decreased from $T_{0}$ to $T_{20}$, just as observed in Experiment $V$ (Figure 25). Concentrations of RDX also decreased, but the difference between $T_{0}$ and $T_{20}$ values was not as great as in Experiment $V$. Concentrations of HMX did not change significantly between $T_{0}$ and $T_{20}$. The TNT transformation product, 4ADNT, increased from $T_{0}$ to $T_{20}$ as in Experiment $V$. The TNT transformation product, 2ADNT, did not increase as much between $\mathrm{T}_{0}$ and $\mathrm{T}_{20}$ in Experiment VI as in Experiment V. Differences in analyte results between the two experiments were relatively small (Figures 20 and 25). 


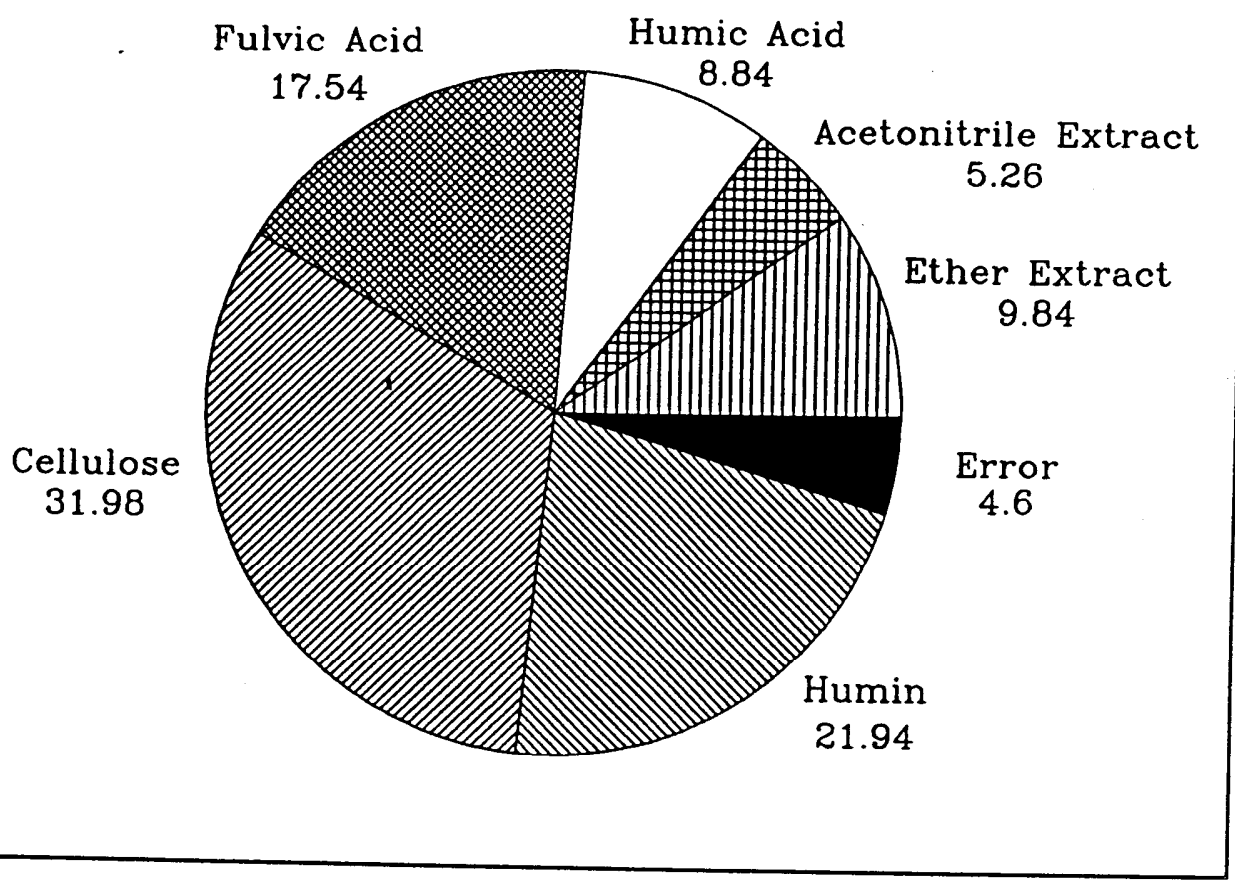

Figure 24. Percent recovery of added radioactivity in each fraction of composted Umatilla soil in Experiment VI. Values (percent of added radioactivity) are means of four replicate compost reactors 


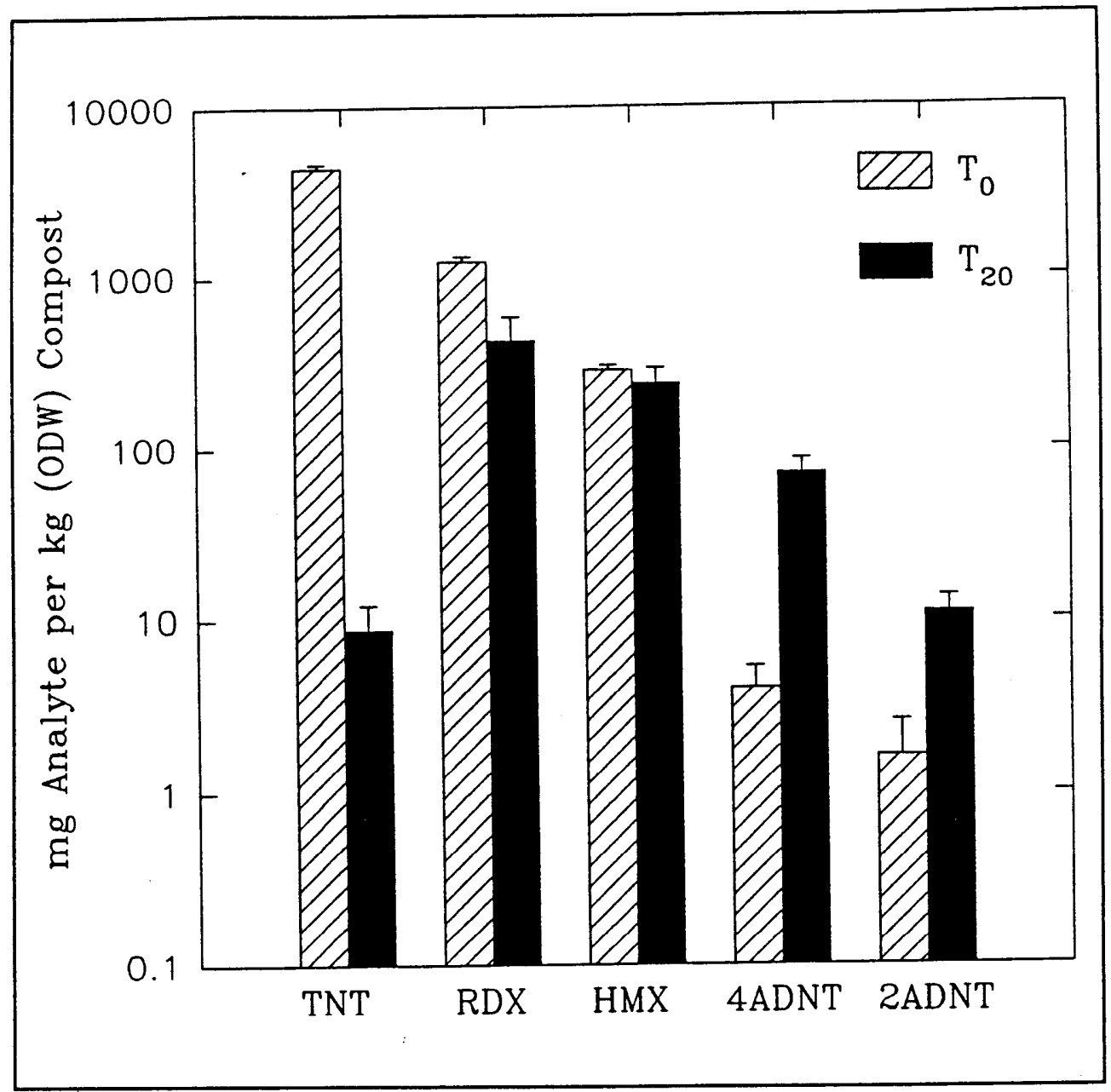

Figure 25. Results of HPLC/UV analysis of composted Umatilla soil at $T_{0}$ and $\mathrm{T}_{20}$ in Experiment $\mathrm{VI}$. Means for all six reactors are shown with standard error bars 


\section{Conclusions}

Experiment I served as a developmental process for composting of TNT at a small scale. The operation of the system and development of procedures for analyzing the compost were improved based on results of Experiment $I$.

Results of Experiment II showed that the microbial activity profiles are typical of composting systems. The small-scale compost reactors were capable of simulating the important parameters of the composting process.

Mass balance determinations from Experiment III indicated no significant losses of TNT or its decomposition products from the compost as volatile organic compounds or carbon dioxide. These results indicate that TNT is not mineralized during composting. No solvent extractable compounds were detected with HPLC, an indication that unbound compounds were absent. As much as 99 percent of the radiolabel was recovered from the compost matrix. Therefore, TNT and its transformation or degradation products have been bound to the compost matrix in some unextractable form.

Composting at the low end of the thermophilic range $\left(46^{\circ} \mathrm{C}\right)$ was achieved in Experiment IV by maintaining compost in a water bath at $55^{\circ} \mathrm{C}$. The experiment allowed refinements in the thermophilic operation of the reactors, which resulted in improved data for the thermophilic experiment with UMDA soil (Experiment VI). Autoclaving of compost material prior to composting for Experiment $\mathrm{V}$ eliminated microbial activity for the first few days only. Since microbial populations recovered so rapidly, no conclusions conceming abiotic transformations of TNT in the compost can be drawn from the results of this experiment. Total solvent extractable radioactivity was less than 20 percent, while most of the radioactivity (nearly 40 percent) was found in the cellulose fraction.

The mean temperature for reactors in Experiment VI $\left(49.4^{\circ} \mathrm{C}\right)$ was within the thermophilic range $\left(45\right.$ to $\left.65^{\circ} \mathrm{C}\right)$. Total recovery of radioactivity from the compost fractions was 96.4 percent. The cellulose fraction, which accounted for 32.0 percent of the radioactivity, was the largest fraction, followed by humin (21.94 percent). Relative amounts of radioactivity recovered from solvent extractable fractions and humic and fulvic acid fractions were similar to those of Experiment V. Little radiolabeled $\mathrm{CO}_{2}$ and no VOCs were detected. 
When UMDA soil was composted under thermophilic conditions (Experiment VI), more than half of the initially added radioactivity was recovered in cellulose and humin fractions in a form not extractable with organic solvents. The implications for the ultimate long-term fate of degradation/transformation products of 'TNT' after composting are unclear. Cellulose, which consists of undecayed or partially undecomposed plant remains, will ultimately degrade in the presence of natural assemblages of cellulolytic bacteria and fungi in soil. The half-life of cellulose in soil is highly variable, ranging from several weeks to many years. This is true because degradation rate is controlled by several soil variables, i.e., available nitrogen, temperature, aeration, moisture, $\mathrm{pH}$, and the presence of other carbohydrates and lignin from the original plant material (Alexander 1977). The reason for residual cellulose in the compost material is that the microbial population has not been sustained at an optimal degradation rate for long enough to degrade all of the cellulose. After microbial populations rise, consume available nutrients, accumulate metabolic waste products and excessive heat, and decline, the composting process stops. Cellulolytic microorganisms may be exhausted after composting, preventing further degradation of the remaining more recalcitrant fractions. The chemical composition of the explosive/cellulose matrix is unknown. Humin is extremely recalcitrant to further decomposition in soils, having a mean residence time of hundreds of years (Stevenson 1989). However, since the nature and characteristics of the explosive/humin fraction is unknown, its long-term stability in compost is also unknown.

Lack of extractablity of explosives and explosives products from the compost matrix creates difficulties in the routine characterization of the final compost material. Analysis of extractable components by HPLC resulted in detection of only two TNT transformation products, 4ADNT and 2ADNT, in extracts. Concentrations of these products failed to account for the total decrease in extractable TNT observed. TNT is not mineralized to VOCs, and almost no $\mathrm{CO}_{2}$ is produced. Instead, only transformation to the solvent extractable products $4 \mathrm{ADNT}$ and $2 \mathrm{ADNT}$ and conjugation to cellulosic, humin, humic acid, and fulvic acid occur. The form and characteristics of the residual products and their long-term stability and environmental safety have not been determined. 


\section{References}

Alexander, M. (1977). Introduction to soil microbiology. 2nd ed., John Wiley and Sons, New York.

American Public Health Association. (1989). Standard methods for the examination of water and wastewater. 17th ed., American Public Health Association, Washington, DC.

Brannon, J. M., and Patrick, W. H., Jr. (1985). "Fixation and mobilization of antimony in sediments," Environmental Pollution (Series B) 9, 107-126.

Day, P. R. (1956). "Report of the Committee on Physical Analyses, 19541955, Soil Science Society of America," Proceedings, Soil Science Society of America 20, 167-169.

Griest, W. H., Tyndall, R. L., Stewart, A. J., Ho, C. -h., Ironside, K. S., Caton, J. E., Caldwell, W. M., and Tan, E. (1991). "Characterization of explosives processing waste decomposition due to composting," ORNL/TM12029, performed by Oak Ridge National Laboratory, Oak Ridge, TN, for U.S. Army Medical Research and Development Command, Fort Detrick, Frederick, MD.

Haug, R. T. (1980). Compost engineering principles and practices. Ann Arbor Science, Ann Arbor, MI.

Magalhaes, A. M. T., Shea, P. J., Jawson, M. D., Wicklund, E. A., and Nelson, D. W. "Practical simulation of composting in the laboratory," Submitted to Waste Management and Research, November, 1991. U.S. Army Medical Research and Development Command, Contact No. DAMD17-89-9031 and NRI-Water Sciences Program, University of Nebraska, Lincoln.

McCormick, N. G., Comell, J. H., and Kaplan, A. M. (1984). "The anaerobic biotransformation of RDX, HMX, and their acetylated derivatives," Natick/TR-85/007, U.S. Army Natick Research and Development Center, Natick, MA.

Patrick, W. H., Jr. (1958). "Modification of method of particle size analysis," Proceedings, Soil Science Society of America 22, 366-332. 
Pennington, J. C. (1988). "Soil sorption and plant uptake of 2,4,6trinitrotoluene," Technical Report EL-88-12, U.S. Army Engineer Waterways Experiment Station, Vicksburg, MS.

Pennington, J. C., and Patrick, W. H., Jr. (1990). "Adsorption and desorption of 2,4,6-trinitrotoluene by soils," Journal of Environmental Quality 19, 559 567.

Plumb, R. H., Jr. (1981). Procedures for handling and chemical analysis of sediments and water analysis. EPA/CE-81-1, May 1981. Environmental Laboratory, U.S. Army Engineer Waterways Experiment Station, Vicksburg, MS.

Rice, J. A., and MacCarthy, P. (1989). "Characterization of a stream sediment humin." Aquatic humic substances: Influence on fate and treatment of pollutants. I. H. Suffet and Patrick MacCarthy, ed., American Chemical Society, Washington, DC.

Stentiford, E. I., Mara, D. D., and Taylor, P. L. (1985). "Forced aeration co-composting of domestic refuse and sewage sludge in static piles." Composting of agricultural and other wastes. J. K. R. Gasser, ed., Elsevier Applied Science Publishers, London, 42-55.

Stevenson, F. J. (1989). Humus chemistry: Genesis, composition, reactions. Wiley-Interscience Publication, John Wiley and Sons, New York.

U. S. Environmental Protection Agency. (1982). Methods for chemical analysis of water and wastes. EPA 600/4-79-020, March 1979 and EPA 600/482-055, December 1982. Environmental Monitoring and Support Laboratory, Cincinnati, $\mathrm{OH}$.

(1990). Test methods for evaluating solid wastes. SW-846, 3rd ed., November 1990 revision, Office of Solid Waste and Emergency Response, Washington, DC.

Williams, R. T., and Marks, P. J. (1991). "Optimization of composting for explosives contaminated soil," CETHA-TS-CR-91053, Prepared for U.S. Army Toxic and Hazardous Materials Agency, Aberdeen Proving Ground, MD, by Roy F. Weston, Inc., West Chester, PA.

Wilson, G. B. (1989). "Combining raw materials for composting," Biocycle, August, 82-85.

Woodward, R. E. (1990). "Evaluation of composting implementation: A literature review," Report No. TCN 89363, U.S. Army Toxic and Hazardous Materials Agency, Aberdeen Proving Ground, MD. 


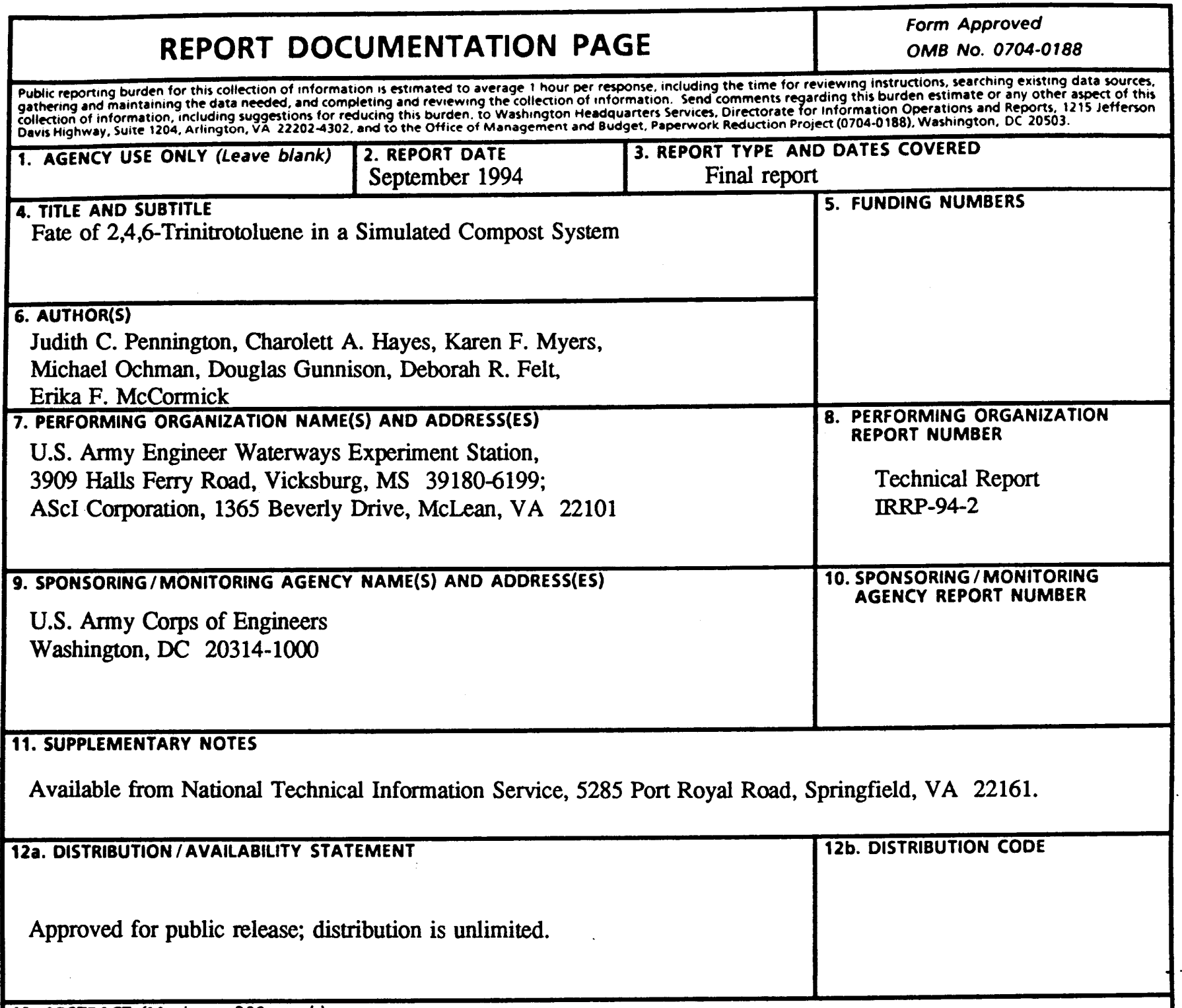

\section{ABSTRACT (Maximum 200 words)}

Composting of explosives-contaminated soils is an economical alternative to other available treatment technologies. Development of a protocol for treatability studies in this work unit required mass balance of $2,4,6$ -

trinitrotoluene (TNT) in the composting process to determine whether environmentally undesirable emissions or residuals are produced. The objective of the study was to develop methods for determining mass balance of TNT in a small-scale $\left(473-\mathrm{cm}^{3}\right)$ compost system. Results of the three small-scale experiments indicated that composting could be simulated at the small scale and that a mass balance for TNT could be determined under mesophilic conditions. Mass balance indicated no significant losses of TNT or its transformation products from the compost as volatile organic compounds or carbon dioxide. No solvent extractable TNT or its transformation products were found. Almost all (70 to 95 percent) of the radioactivity remained in the compost.

The fourth small-scale experiment was designed to simulate thermophilic conditions using an uncontaminated soil; the fifth investigated the effects of reducing microbial activity on the fate of TNT in the compost matrix; and the sixth simulated thermophilic conditions in a contaminated soil from Umatilla Army Depot Activity, Umatilla, OR. The composted material was subjected to a fractionation procedure to determine where in the final matrix the TNT or its transformation products remained.

(Continued)

\begin{tabular}{|c|c|}
\hline $\begin{array}{l}\text { 14. SUBJECT TERMS } \\
\text { Composting } \\
\text { Explosives } \\
\text { TNT }\end{array}$ & \\
\hline $\begin{array}{l}\text { 17. SECURITY CLASSIFICATION } \\
\text { OF REPORT } \\
\text { UNCLASSIFIED }\end{array}$ & $\begin{array}{l}\text { 18. SECURITY CLASSIFICATION } \\
\text { OF THIS PAGE } \\
\text { UNCLASSIFIED }\end{array}$ \\
\hline
\end{tabular}

\begin{tabular}{|c|c|}
\hline & $\begin{array}{l}\text { 15. NUMBER OF PAGES } \\
60\end{array}$ \\
\hline & 16. PRICE CODE \\
\hline $\begin{array}{l}\text { 19. SECURITY CLASSIFICATION } \\
\text { OF ABSTRACT }\end{array}$ & 20. LIMITATION OF ABSTRACT \\
\hline & $\begin{array}{l}\text { indard form } 298 \text { (Rev. 2-89) } \\
\text { cribed by ANSi std. } 239.18 \\
102\end{array}$ \\
\hline
\end{tabular}




\section{3. (Concluded)}

Results of these experiments indicated that thermophilic conditions could be simulated at the small scale, once key operational conditions were optimized. Fractionation studies indicated that more than half of the radioactivity from added radiolabeled TNT was recovered in the cellulose and humin fractions. The chemical composition and long-term stability of the explosives/cellulose and the explosives/humin matrices resulting from composting of explosives-contaminated soils is unknown. Furthermore, the environmental safety of decomposition products released over the long-term when these matrices ultimately decompose are currently undefined. 